\title{
Design and characterization of protein-quercetin bioactive nanoparticles
}

\author{
Ru Fang ${ }^{1}$, Hao Jing ${ }^{1 *}$, Zhi Chai ${ }^{1}$, Guanghua Zhao ${ }^{1}$, Serge Stoll², Fazheng Ren ${ }^{1}$, Fei Liu ${ }^{1}$ and Xiaojing Leng ${ }^{1 *}$
}

\begin{abstract}
Background: The synthesis of bioactive nanoparticles with precise molecular level control is a major challenge in bionanotechnology. Understanding the nature of the interactions between the active components and transport biomaterials is thus essential for the rational formulation of bio-nanocarriers. The current study presents a single molecule of bovine serum albumin (BSA), lysozyme (Lys), or myoglobin (Mb) used to load hydrophobic drugs such as quercetin $(\mathrm{Q})$ and other flavonoids.

Results: Induced by dimethyl sulfoxide (DMSO), BSA, Lys, and Mb formed spherical nanocarriers with sizes less than $70 \mathrm{~nm}$. After loading Q, the size was further reduced by $30 \%$. The adsorption of Q on protein is mainly hydrophobic, and is related to the synergy of Trp residues with the molecular environment of the proteins. Seven $\mathrm{Q}$ molecules could be entrapped by one Lys molecule, 9 by one Mb, and 11 by one BSA. The controlled releasing measurements indicate that these bioactive nanoparticles have long-term antioxidant protection effects on the activity of $\mathrm{Q}$ in both acidic and neutral conditions. The antioxidant activity evaluation indicates that the activity of $\mathrm{Q}$ is not hindered by the formation of protein nanoparticles. Other flavonoids, such as kaempferol and rutin, were also investigated.
\end{abstract}

Conclusions: BSA exhibits the most remarkable abilities of loading, controlled release, and antioxidant protection of active drugs, indicating that such type of bionanoparticles is very promising in the field of bionanotechnology.

\section{Background}

Over the last several decades, the development of nanoparticles as drug delivery systems has gained considerable interest. Nanotoxicology research has indicated that [1] not only pharmacological properties but also the biodegradability, biocompatibility, and nontoxicity should be considered in such new systems. Therefore, synthetic macromolecules, such as the amphiphilic hyperbranched multiarm copolymers (HPHEEP-star-PPEPs) [2], poly(2ethyl-2-oxazoline)-b-poly(D,L-lactide) [3], and polyethylene glycol [4], are often investigated; replacing these synthetic materials with natural proteins, which are more likely to be accepted by people, has become the focus of many research studies [5-9]. However, the microstructure of natural substances is generally

\footnotetext{
* Correspondence: hao.haojing@gmail.com; xiaojing.leng@gmail.com ${ }^{1}$ CAU and ACC Joint Laboratory of Space Food, College of Food Science and Nutritional Engineering, China Agricultural University, Key Laboratory of Functional Dairy Science of Beijing and the Ministry of Education, Beijing Higher Institution Engineering Research Center of Animal Product, No.17 Qinghua East Road, Haidian, Beijing 100083, China

Full list of author information is available at the end of the article
}

complex and difficult to control; progress largely depends on knowledge of the physiochemical properties of the materials.

The potential therapeutic usefulness of albumin, such as bovine serum albumin (BSA), is high; it possesses the ability to transport fatty acids and many other endogenous or exogenous compounds throughout the body $[10,11]$. Using a coacervation process, i.e., desolvation with ethanol and then solidification with glutaraldehyde, BSA can form nanoparticles [7]. Hydrophilic drugs, such as phosphodiester oligonucleotide, 5-fluorouracil, and sodium ferulate, among others, can be incorporated into the matrix or adsorbed on the surface of nanoparticles [7-9]. However, the molecular sizes obtained from such a process are often larger than $70 \mathrm{~nm}$; such particles cannot be used to entrap hydrophobic drugs, thereby restricting the development of bio-nanocarriers.

The present study proposes a novel method for designing a small bioactive nanoparticle using BSA as a carrier to deliver hydrophobic drugs. Quercetin (Q), a polyphenol widely distributed in vegetables and plants,

\section{() Biomed Central}

(c) 2011 Fang et al; licensee BioMed Central Ltd. This is an Open Access article distributed under the terms of the Creative Commons Attribution License (http://creativecommons.org/licenses/by/2.0), which permits unrestricted use, distribution, and reproduction in any medium, provided the original work is properly cited. 
is used here as a model of hydrophobic drugs. Q exhibits anti-oxidative, free radical scavenging, anticancer, and antiviral activities [12]. However, the poor solubility and low stability of $\mathrm{Q}$ in aqueous alkaline medium [13] restrict the application of this type of drug in oral use. Dimethyl sulfoxide (DMSO), one of the most versatile organic solvents in biological science that can accept hydrogen-bond and interact with the hydrophobic residues of proteins [14], is used here to dissolve Q, and synthesize a novel nanocarrier with interesting drug delivery capabilities. Some studies have reported that BSA interacts with Q through tryptophan (Trp) $[15,16]$. BSA is a monomeric globular protein formed from 583 amino acid residues, containing two Trps, one of which is located in the inner hydrophobic pocket, corresponding to the so-called site II. Site II is a specific site for hydrophobic drugs due to its hydrophobicity [11,17]. To confirm the feasibility of the Trp transport functionality, lysozyme (Lys) and myoglobin (Mb) were also used in this work for comparison with BSA. Figure 1 exhibits the molecular structures of Lys, Mb, and BSA. Lys is a small monomeric globular protein formed from 129 amino acid residues, and contains six Trps. This protein is known to bind various small ligands, such as metal ions, non-metal ions, dyes, and numerous pharmaceuticals [18-20]. $\mathrm{Mb}$ is a small heme protein for oxygen storage and transport. It contains a single polypeptide chain of 153 amino acid residues and two Trps. The

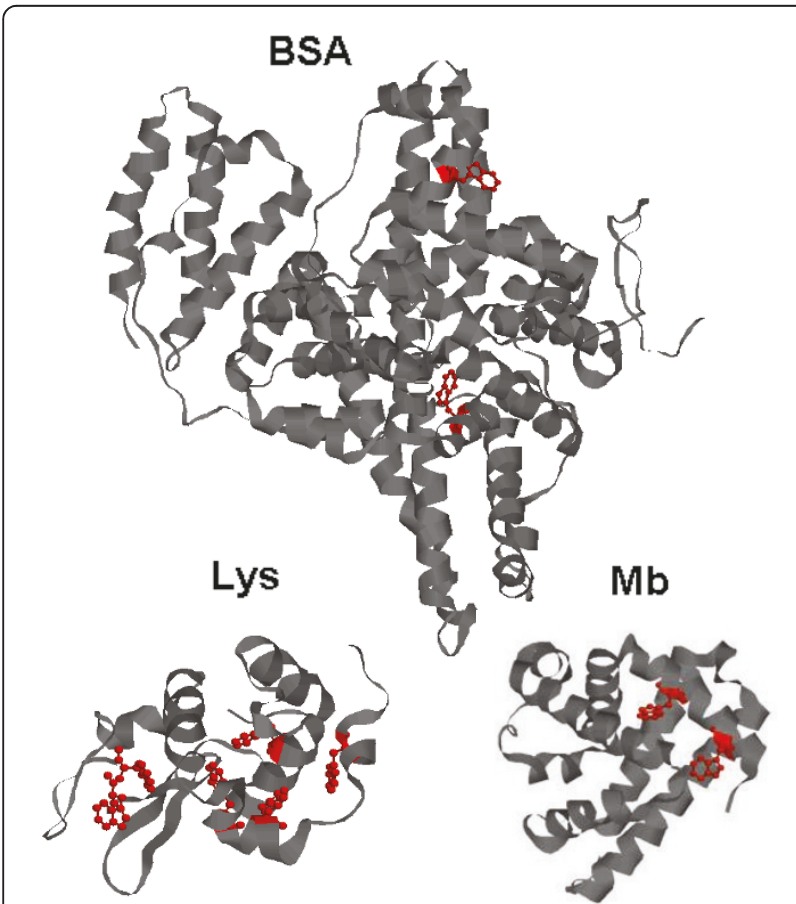

Figure 1 Schematic drawing of the Lys, Mb, and BSA molecules. Trp residues are marked in red. polypeptide chain provides a nonpolar pocket to accommodate and stabilize the porphyrin ring [21-23].

In the present study, the $\mathrm{Q}$ binding and releasing capacity of Lys and $\mathrm{Mb}$ are compared with those of BSA. The salting out method was combined with UVVis spectrometry to determine the binding capacity of the proteins. The release of $\mathrm{Q}$ from nanocarriers was detected in acidic and neutral conditions. The antioxidant properties of the bound $\mathrm{Q}$ in proteins were evaluated by 2,2-diphenyl-1-picrylhydrazyl (DPPH) and 2,2'azino-bis(3-ethylbenzothiazoline-6-sulfonic acid) (ABTS) radicals. Raman, fluorescence, and UV-Vis spectroscopy were combined to study the secondary and tertiary structures of the protein aggregates.

\section{Results and Discussion}

\section{Size and Zeta Potential Measurements}

Scanning transmission electron microscopy (STEM) and dynamic light scattering (DLS) were combined to analyze the size and conformational features of the BSA, Lys, and Mb systems, as shown in Figures 2, 3, 4, \&5. STEM micrographs show that the native BSA, Lys, and $\mathrm{Mb}$ molecules (without DMSO) were cross-linked, and formed loose aggregates (Figures 2A, $\mathbf{A}^{\prime}$, and $\left.\mathbf{A}^{\prime \prime}\right)$. When the added amount of DMSO was over $10 \%(\mathrm{v} / \mathrm{v})$, DMSO-inducing protein (BSA, Lys, or Mb) nanoparticles (D-BSA, D-Lys, or D-Mb) formed, showing compact and spherical aggregates (Figures $2 \mathrm{~B}, \mathrm{~B}$, and $\left.2 \mathrm{~B}^{\prime \prime}\right)$. After adding $1.5 \times 10^{-4} \mathrm{~mol} / \mathrm{L} \mathrm{Q}$ solution prepared with $10 \%$ DMSO, spherical and compact Q loaded protein (BSA, Lys, or Mb) nanoparticles (D-BSA-Q, D-Lys-Q, or D-Mb-Q) also occurred (Figures $2 \mathrm{C}, \mathrm{C}$, and $2 \mathrm{C}^{\prime \prime}$ ), but their size decreased compared with the system without $\mathrm{Q}$, particularly the D-BSA-Q aggregates, which markedly decreased in size.

The autocorrelation function curve (ACF) of light scattering, $G(\tau)$ ( $\tau$ is delay time), was used to determine the hydrodynamic particle sizes of the system [24,25]. The size of D-BSA (Figures 3A and 3A') and D-Lys (Figures $4 \mathrm{~A}$ and $4 \mathrm{~A}^{\prime}$ ) was less than $50 \mathrm{~nm}$ when the concentration of DMSO was less than $40 \%$; this increased markedly with increasing DMSO concentrations. The size of $\mathrm{D}-\mathrm{Mb}$ was maintained at about $70 \mathrm{~nm}$ when the DMSO concentration was less than $20 \%$; serious precipitation is produced with concentrations of DMSO over $40 \%$ (Figures 5A and 5A'). Therefore, the concentration of DMSO was maintained at $10 \%$, but the concentration of $\mathrm{Q}$ was changed. The sizes of D-BSA-Q (Figures 3B and $3 \mathrm{~B}^{\prime}$ ), D-Lys-Q (Figures $4 \mathrm{~B}$ and $4 \mathrm{~B}^{\prime}$ ), and $\mathrm{D}-\mathrm{Mb}-\mathrm{Q}$ (Figures 5B and 5B') became smaller than those of $\mathrm{D}-\mathrm{BSA}$, D-Lys, and D-Mb, respectively. Moreover, the sizes of both $\mathrm{D}$-Lys- $\mathrm{Q}$ and $\mathrm{D}-\mathrm{Mb}-\mathrm{Q}$ were generally larger than D-BSA-Q. These observations were in accordance with the STEM analysis. 

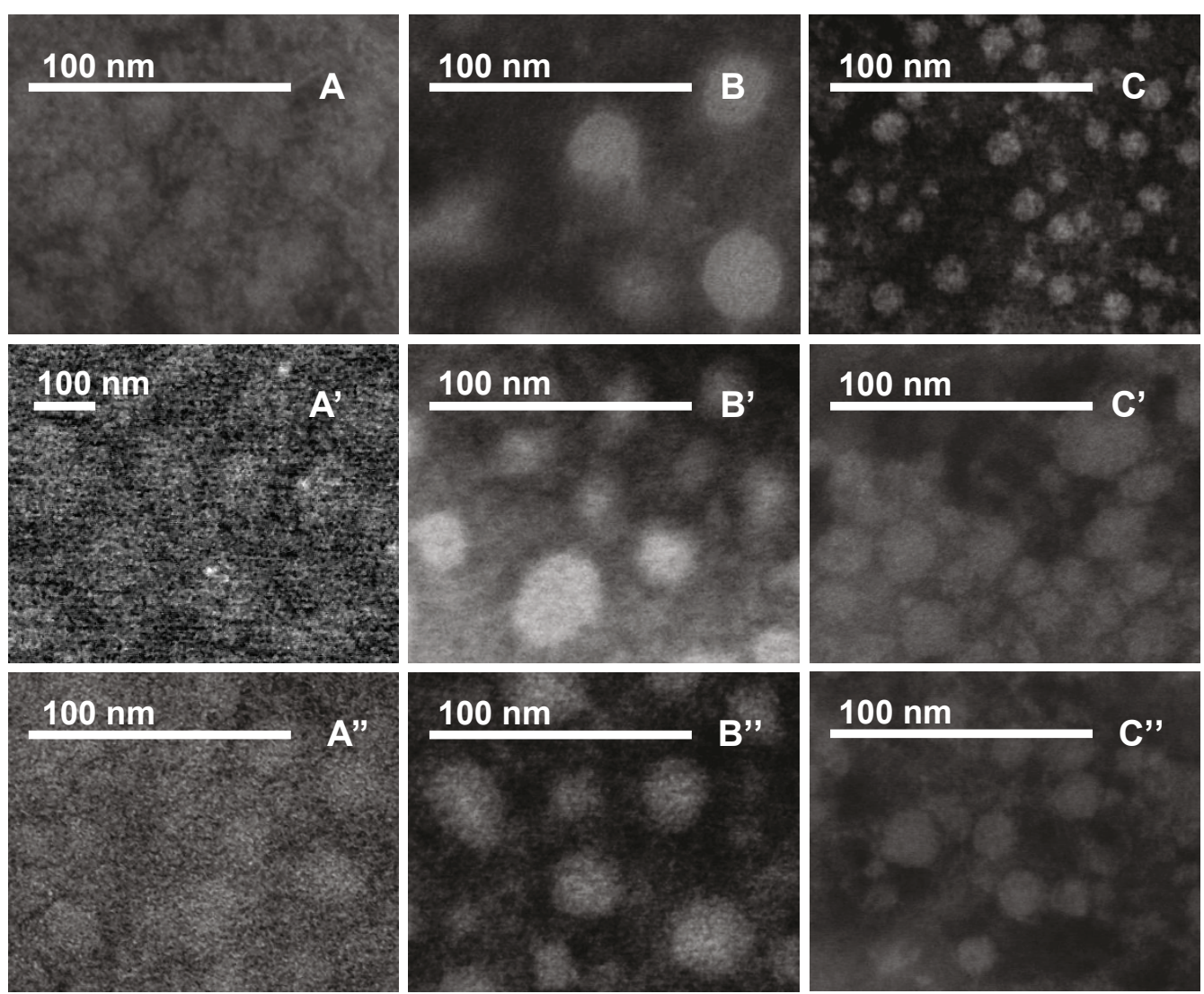

Figure 2 STEM images of BSA, Lys, and Mb system. The concentration of BSA, Lys, or Mb was $1.5 \times 10^{-5}$ mol/L. (A) Native BSA, no DMSO and Q were added; (B) 10\% DMSO and BSA; (C) 10\% DMSO, $1.5 \times 10^{-4}$ mol/L Q and BSA; ( $A^{\prime}$ ) Native Lys, no DMSO and Q were added; (B') 10\% DMSO and Lys; (C') 10\% DMSO, $1.5 \times 10^{-4} \mathrm{~mol} / \mathrm{L} \mathrm{Q}$ and Lys; ( $\left.\mathrm{A}^{\prime \prime}\right)$ Native Mb, no DMSO and Q were added; (B") $10 \%$ DMSO and Mb; (C') $10 \%$ DMSO, $1.5 \times 10^{-4} \mathrm{~mol} / \mathrm{L} \mathrm{Q}$ and $\mathrm{Mb}$.
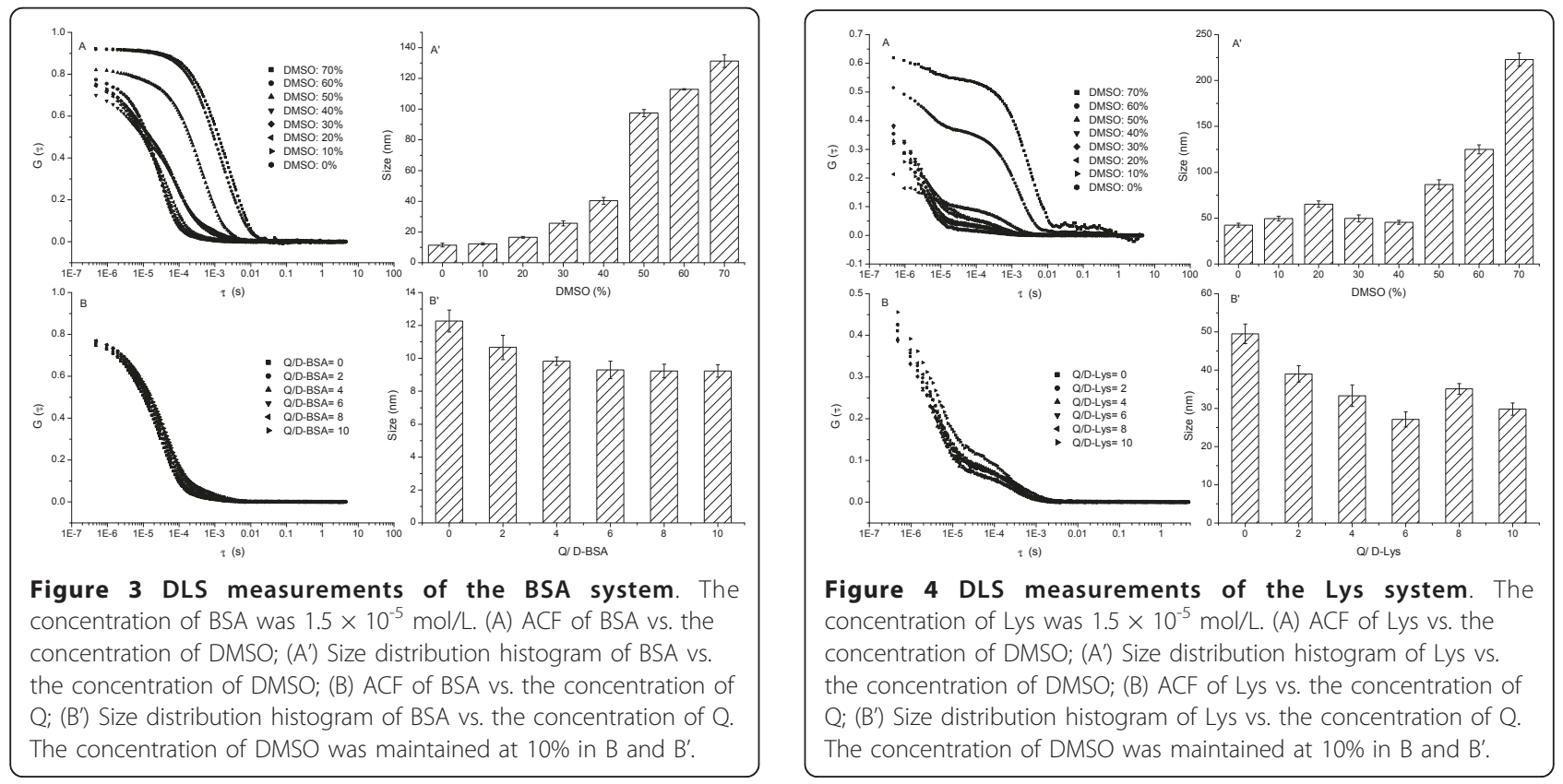


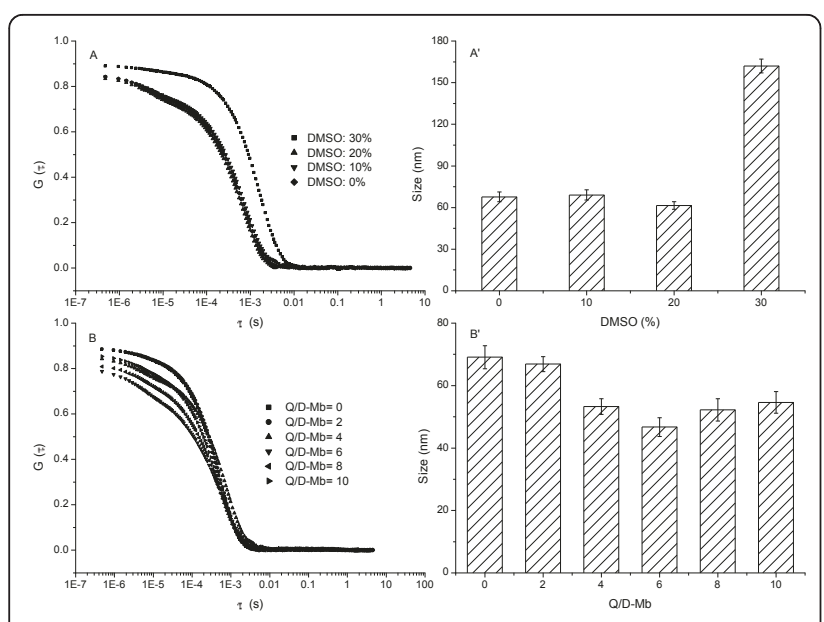

Figure 5 DLS measurements of the Mb system. The concentration of Mb was $1.5 \times 10^{-5} \mathrm{~mol} / \mathrm{L}$. (A) ACF of Mb vs. the concentration of DMSO; ( $\left.A^{\prime}\right)$ Size distribution histogram of Mb vs. the concentration of DMSO; (B) ACF of Mb vs. the concentration of $\mathrm{Q}$; ( $\left.\mathrm{B}^{\prime}\right)$ Size distribution histogram of $\mathrm{Mb}$ vs. the concentration of $\mathrm{Q}$. The concentration of DMSO was maintained at $10 \%$ in B and $\mathrm{B}^{\prime}$.

Figure 6 shows the variation of the zeta potential of the BSA, Lys, and Mb systems versus the concentration of DMSO (A, A', and A") and Q (B, B', and B'). With increasing DMSO concentration, the zeta potential values of D-BSA, D-Lys, and D-Mb tended to decline to zero (A, $\mathbf{A}^{\prime}$ and $\left.\mathbf{A}^{\prime \prime}\right)$. The loss of surface charges indicates that the protein aggregations were caused by the gradually enhanced hydrophobic forces compared with electrostatic ones. Upon addition of $\mathrm{Q}$, the zeta potential values of D-BSA-Q, D-Lys-Q, and D-Mb-Q became $-12.5,2.5$, and $-5 \mathrm{mV}$ (B, B', and B'), respectively. Size analysis showed that D-BSA-Q, D-Lys-Q, and D-Mb-Q were smaller than D-BSA, D-Lys, and D-Mb, respectively, indicating that protein aggregation was hindered by electrostatic repulsion in these systems compared with the system without $\mathrm{Q}$. The corresponding potential variations could be related to the features of the amino acid residues of the polypeptide backbone and protein structural transformation caused by Q. To attain a better understanding of the changes in the secondary and tertiary structures of the protein molecules during aggregation, Raman, fluorescence, and UV-Vis spectroscopy were performed. The molecular mass of native BSA, Lys, and $\mathrm{Mb}$ molecules $\left(\mathrm{M}_{\mathrm{BSA}}, \mathrm{M}_{\mathrm{Lys}}\right.$, and $\left.\mathrm{M}_{\mathrm{Mb}}\right)$, D-BSA-Q, D-Lys-Q, and $\mathrm{D}-\mathrm{Mb}-\mathrm{Q}$ prepared with $1.5 \times 10^{-4} \mathrm{~mol} / \mathrm{L} \mathrm{Q}$ and $10 \%$ DMSO $\left(\mathrm{M}_{\mathrm{D}-\mathrm{BSA}-\mathrm{Q}}, \mathrm{M}_{\mathrm{D}-\mathrm{Lys}-\mathrm{Q}}\right.$, and $\left.\mathrm{M}_{\mathrm{D}-\mathrm{Mb}-\mathrm{Q}}\right)$, were determined using the DLS method. The ratio of $\mathrm{M}_{\mathrm{D}-\mathrm{BSA}-\mathrm{Q}} /$ $\mathrm{M}_{\mathrm{BSA}}$ obtained was found to vary between 1.1 and 2.2, indicating that one BSA nanocarrier consisted of not more than 2 BSA molecules. However, the obtained ratios of $\mathrm{M}_{\mathrm{D}-\text { Lys-Q }} / \mathrm{M}_{\text {Lys }}$ and $\mathrm{M}_{\mathrm{D}-\mathrm{Mb}-\mathrm{Q}} / \mathrm{M}_{\mathrm{Mb}}$ were 4.8 and 5.1, respectively, indicating that one Lys nanocarrier consisted

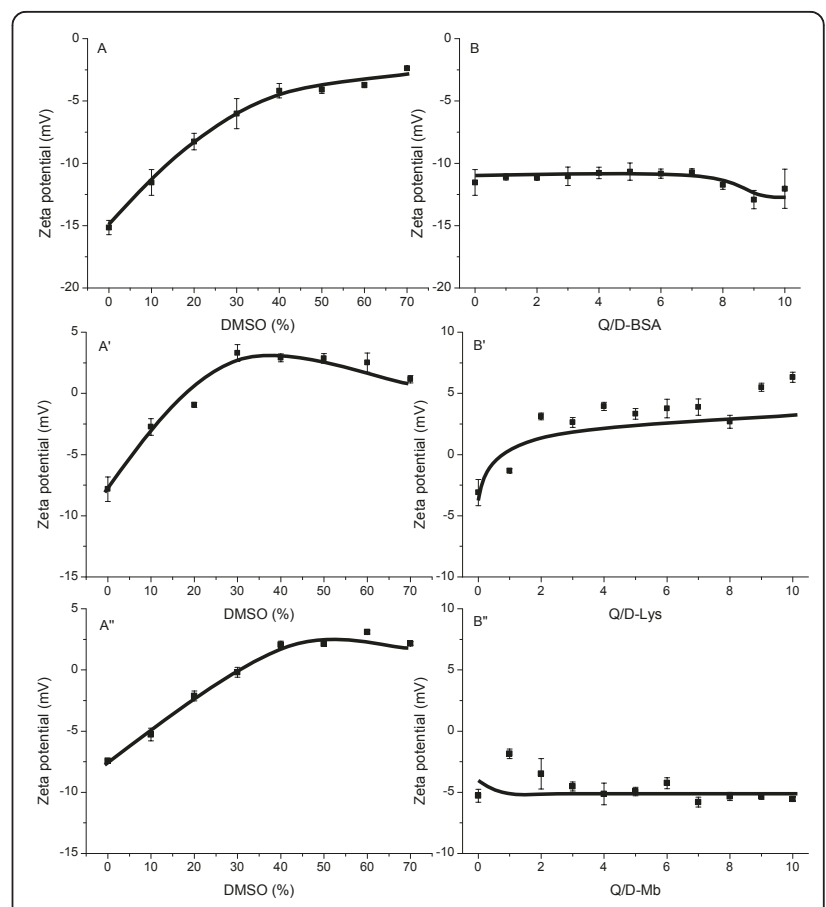

Figure 6 Zeta potential measurements of BSA, Lys, and Mb systems. The concentration of BSA, Lys, or Mb was $1.5 \times 10^{-5}$ $\mathrm{mol} / \mathrm{L}$. (A) Zeta potential of BSA vs. the concentration of DMSO; (B) Zeta potential of BSA vs. the concentration of $\mathrm{Q}$. ( $\mathrm{A}^{\prime}$ ) Zeta potential of Lys vs. the concentration of DMSO; ( $\left.B^{\prime}\right)$ Zeta potential of Lys vs. the concentration of $\mathrm{Q}$. ( $\left.\mathrm{A}^{\prime \prime}\right)$ Zeta potential of Mb vs. the concentration of DMSO; ( $\left.\mathrm{B}^{\prime \prime}\right)$ Zeta potential of Mb vs. the concentration of $\mathrm{Q}$. The concentration of DMSO was kept constant at $10 \%$ in $B, B^{\prime}$, and $B^{\prime \prime}$. Solid lines were used to illustrate the trends of the experimental data (in symbols) in both $A, A^{\prime}, A^{\prime \prime}, B, B^{\prime}$, and $B^{\prime \prime}$.

of more than 4 Lys molecules, and one $\mathrm{Mb}$ nanocarrier consisted of more than $5 \mathrm{Mb}$ molecules.

\section{Laser Raman spectroscopy}

Raman spectroscopy was employed to investigate changes in the secondary and tertiary structures of the protein molecules during aggregation. Figure 7 compares the Raman spectra of native BSA and D-BSA in the $1800-400 \mathrm{~cm}^{-1}$ region. Consistent with the literature $[26,27]$, the secondary structure of native BSA was largely $\alpha$-helical in form; this was supported by an amide I signal at $1654 \mathrm{~cm}^{-1}$. The decrease in band intensity with DMSO concentration presented in Table 1 indicates the loss of the $\alpha$-helix during aggregation. Meanwhile, the broadening of this band and the increase of the band intensity at $1665 \mathrm{~cm}^{-1}$ implies the increase of the random-coil content in the protein structure [26]. The coincident trends were observed in Lys (Figure 8) and $\mathrm{Mb}$ (Figure 9) systems. Over 30\% of the secondary structure of native Lys presented in random coil conformation, as supported by an amide I signal at $1665 \mathrm{~cm}^{-1}$ and an amide III signal at $1245 \mathrm{~cm}^{-1}$. The change in intensity of 


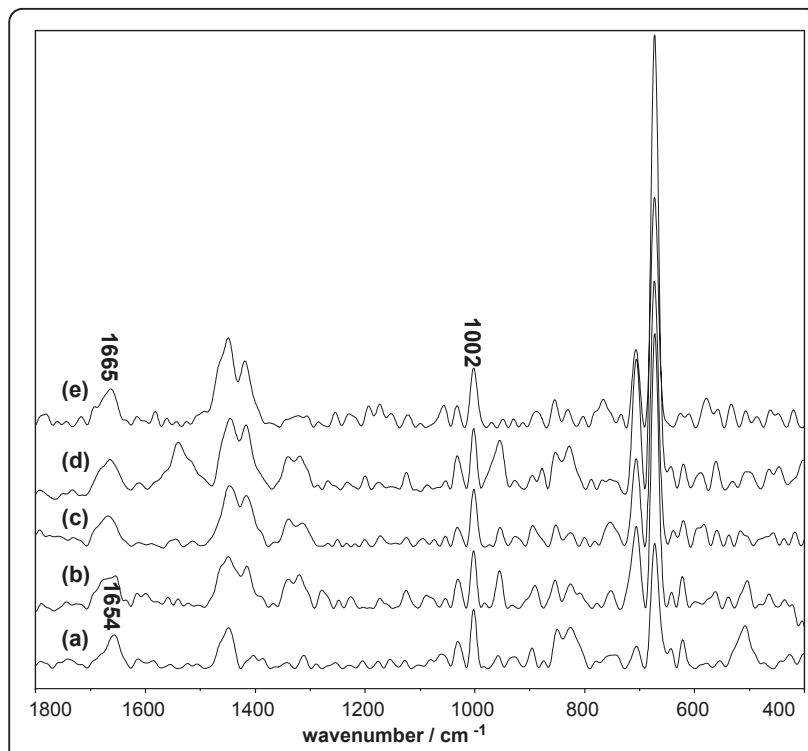

Figure 7 Raman spectrum of BSA system vs. the concentration of DMSO. The concentration of BSA was $1.5 \times 10^{-5} \mathrm{~mol} / \mathrm{L}$. (a) Native BSA; (b) BSA and 10\% DMSO; (c) BSA and 30\% DMSO; (d) BSA and 50\% DMSO; (e) BSA and 70\% DMSO.

these bands, presented in Table 2, shows the increase of random-coil in protein microstructures with DMSO. The secondary structure of the native Mb was largely $\alpha$ helical in form, as supported by an amide I signal at $1659 \mathrm{~cm}^{-1}$. Similar to the case of D-BSA, the disappearance of this band with DMSO concentration, presented in Table 3, indicates the decrease of $\alpha$-helix during aggregation. The increase in intensity of the band at $1669 \mathrm{~cm}^{-1}$ implies an increase in random-coil content in the protein structure during aggregation. The loss of the $\alpha$-helix is attributed to the competition between the $\mathrm{S}=$ $\mathrm{O}$ group of DMSO and the $\mathrm{C}=\mathrm{O}$ groups of protein for the amide's hydrogen molecules, resulting in the partial unfolding of the polypeptide chain, exposure of the internal hydrophobic groups, and promotion of protein aggregation by hydrophobic effects and $\mathrm{H}$-bonding $[14,28]$. This belief is supported by the zeta potential measurements in the previous section.

The Raman spectra of D-BSA-Q and D-Lys-Q are shown in Figures 10 and 11, respectively; here, the

Table 1 Intensities ${ }^{\text {a }}$ of Raman Band of BSA system

\begin{tabular}{lll}
\hline & $1665 \mathbf{c m}^{-1}$ & $1654 \mathbf{c m}^{-1}$ \\
\hline BSA & N. D. & 0.54 \\
BSA + DMSO (10\%) & 0.31 & 0.34 \\
BSA + DMSO (30\%) & 0.36 & 0.23 \\
BSA + DMSO (50\%) & 0.39 & 0.22 \\
BSA + DMSO (70\%) & 0.41 & N. D. \\
\hline
\end{tabular}

antegrated intensity (peak intensity) relative to that of the phenylalanine band at $1002 \mathrm{~cm}^{-1}$. N. D. = not detected. The concentration of BSA was $1.5 \times$ $10^{-5} \mathrm{~mol} / \mathrm{L}$.

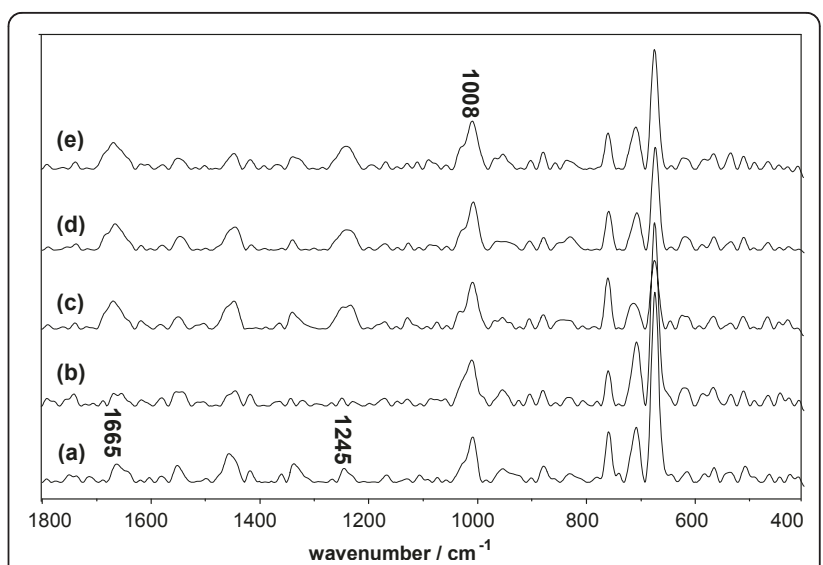

Figure 8 Raman spectrum of Lys system vs. the concentration of DMSO. The concentration of Lys was $1.5 \times 10^{-5} \mathrm{~mol} / \mathrm{L}$. (a) Native Lys; (b) Lys and 10\% DMSO; (c) Lys and 30\% DMSO; (d) Lys and 50\% DMSO; (e) Lys and 70\% DMSO.

concentration of DMSO was kept constant at $10 \%$. The band at $1611 \mathrm{~cm}^{-1}$ (Figures 10 and 11), which is sensitive to the bound ligands, is a marker of the orientation of the indole ring of Trp with respect to the $C \alpha$ atom of the peptide backbone [29]. The increase in band intensities shown in Tables 4 and 5 indicates that the added Q led to the reorientation of the indole ring through the adjustment in the torsional angle of the side chain. The bands near 1319 and $600 \mathrm{~cm}^{-1}$ were ascribed to aliphatic $\mathrm{CH}_{2}$ twisting deformations and the pyrrole ring skeletal of Trp [30], respectively. The significant increase in their intensities with increasing $Q$ proved the interactions between Trp and Q (Figures 10 and 11, Tables 4 and 5). The bands near 1339 [31,32] and $758[33] \mathrm{cm}^{-1}$ have been found to be indicators of the hydrophobicity of the Trp environment, and a decrease in these band

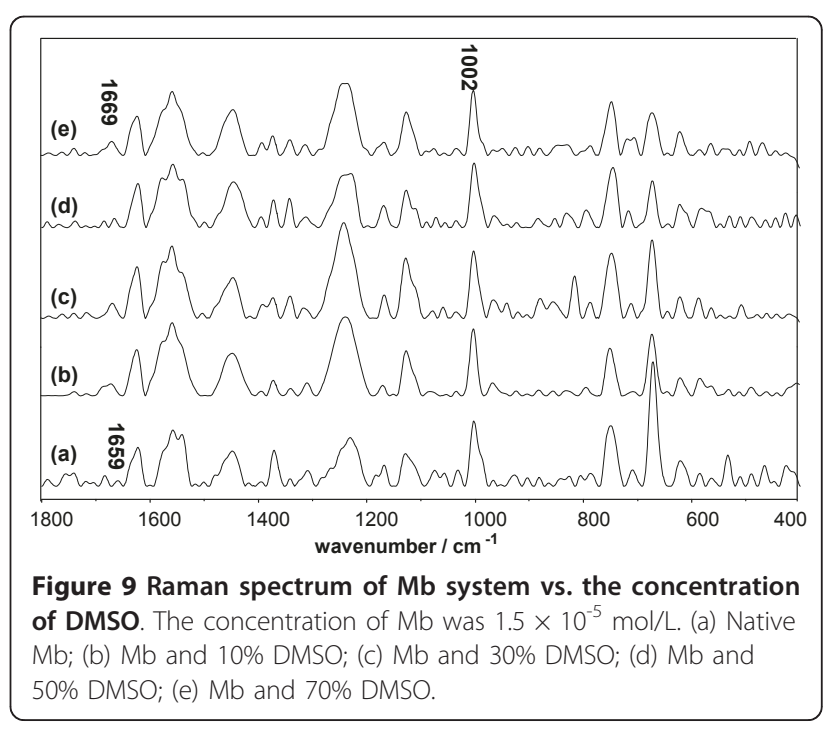


Table 2 Intensities ${ }^{\mathrm{a}}$ of Raman Band of Lys system

\begin{tabular}{lll}
\hline & $\mathbf{1 6 6 5} \mathbf{~ c m}^{-\mathbf{1}}$ & $\mathbf{1 2 4 5} \mathbf{c m}^{-\mathbf{1}}$ \\
\hline Lys & 0.41 & 0.31 \\
Lys + DMSO (10\%) & 0.27 & 0.17 \\
Lys + DMSO (30\%) & 0.60 & 0.47 \\
Lys + DMSO (50\%) & 0.55 & 0.42 \\
Lys + DMSO (70\%) & 0.56 & 0.48 \\
\hline
\end{tabular}

antegrated intensity (peak intensity) relative to that of the phenylalanine band at $1008 \mathrm{~cm}^{-1}$. The concentration of Lys was $1.5 \times 10^{-5} \mathrm{~mol} / \mathrm{L}$.

intensities (Figures 10 and 11, Tables 4 and 5) indicates that the molecular environment of Trp is more hydrophobic due to the interactions between the indole ring and $\mathrm{Q}$.

The intensity of the band near $1420 \mathrm{~cm}^{-1}$, which was observed in the Raman spectra of D-BSA-Q (Table 4), increased with $\mathrm{Q}$, indicating exposure of the ionized carboxyl group $\left(\mathrm{COO}^{-}\right)$of aspartic (Asp) and glutamic acid (Glu) residues $[29,34,35]$, the $\mathrm{PK}_{\alpha}$ values of which are 3.9 and 4.3, respectively. These resulted in the negative charges of the particles. The intensity of the band at $1500 \mathrm{~cm}^{-1}$ increased with Q (Table 5), indicating exposure of the ionized amino group $\left(\mathrm{NH}_{3}{ }^{+}\right)$of lysine (Lys) and arginine (Arg) residues, the $\mathrm{PK}_{\alpha}$ values of which are 10.5 and 12.5 , respectively [36]. These resulted in the positive charges of the particles. The negative or positive charges weakened the tendency of the particles to undergo aggregation. This conclusion is in agreement with the zeta potential measurements in the previous section.

$\mathrm{Mb}$ consists of eight helical regions and a non-covalent bound heme prosthetic group, which is buried in a relatively hydrophobic pocket interior of the protein. With laser excitation, the Raman bands of the porphyrin skeleton, appearing between 1650 and $1100 \mathrm{~cm}^{-1}$, become very intense and disturb the signals of the other bands (Figure 12). This phenomenon brings difficulty in the analysis in this region [21,37]. In addition, the approach of two Trp residues to the heme results in a partial energy transfer of the chromophoric group in Trp [37], and causes the Raman bands arising from Trp, such as those at 1611,1319 , and $600 \mathrm{~cm}^{-1}$, to become very weak (Figure 12).

Table 3 Intensities ${ }^{a}$ of Raman Band of Mb system

\begin{tabular}{lll}
\hline & $1669 \mathrm{~cm}^{-1}$ & $1659 \mathrm{~cm}^{-1}$ \\
\hline $\mathrm{Mb}$ & N.D. & 0.08 \\
$\mathrm{Mb}+\mathrm{DMSO}(10 \%)$ & 0.18 & N.D. \\
$\mathrm{Mb}+\mathrm{DMSO}(30 \%)$ & 0.22 & N.D. \\
$\mathrm{Mb}+\mathrm{DMSO}(50 \%)$ & 0.14 & N.D. \\
\hline
\end{tabular}

antegrated intensity (peak intensity) relative to that of the phenylalanine band at $1002 \mathrm{~cm}^{-1}$. N. D. = not detected. The concentration of Mb was $1.5 \times$ $10^{-5} \mathrm{~mol} / \mathrm{L}$.

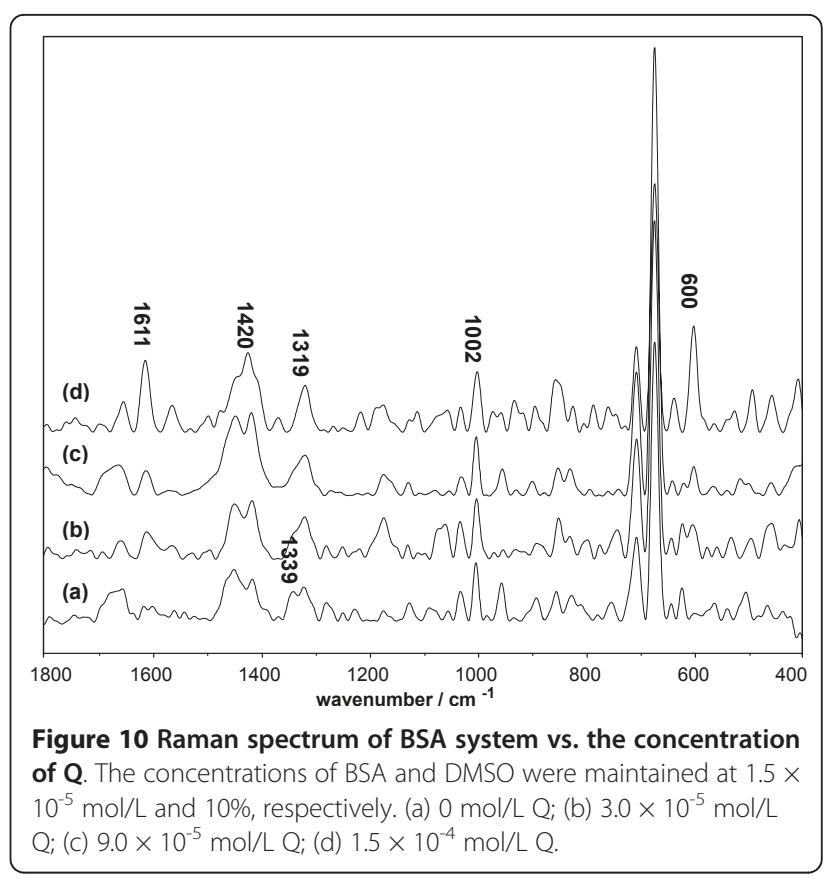

Fluorescence Spectroscopy

Figure 13 compares the fluorescence spectra of the D-BSA (A), D-Lys (A'), D-Mb (A'), D-BSA-Q (B), D-Lys-Q (B'), and D-Mb-Q (B') versus the concentration of DMSO or Q. At an excitation wavelength of 280 $\mathrm{nm}$, native BSA and Lys showed maximum intrinsic fluorescence at $340 \mathrm{~nm}$, while $\mathrm{Mb}$ showed a maximum at $328 \mathrm{~nm}$; these are believed to be caused by Trp residues. Of the two Trp residues in BSA, one is located near the surface of the protein molecule; in the case of Lys [38] and Mb [37], three and one Trp residues are respectively located near the surfaces of the molecules. The fluorescence of tyrosine (Tyr) residues $(304 \mathrm{~nm}$ ) was extremely weak and could be neglected. A slight

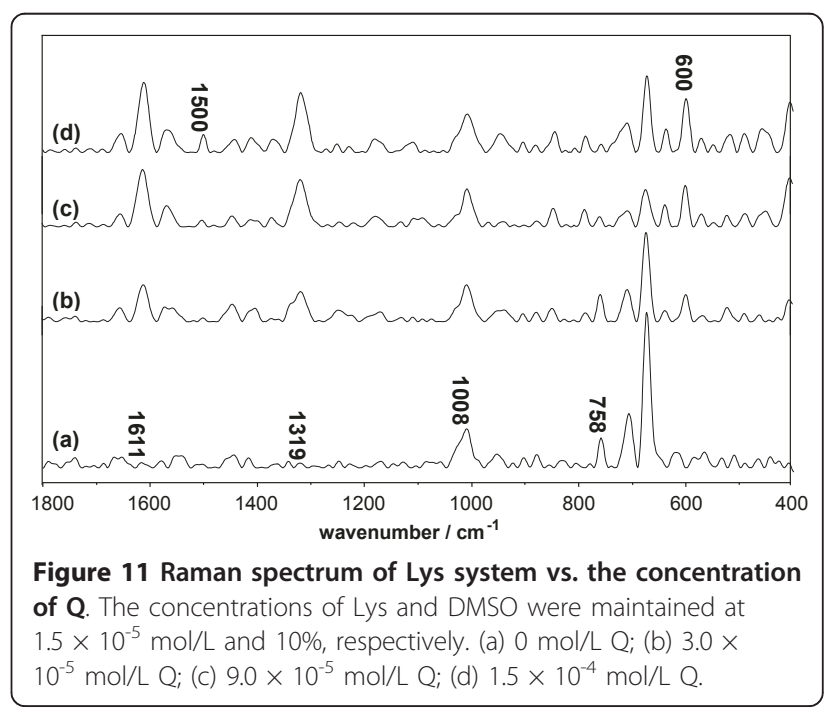


Table 4 Intensities ${ }^{\mathrm{a}}$ of Raman Band in BSA

\begin{tabular}{|c|c|c|c|c|c|}
\hline & ${ }_{1}^{1613 \mathrm{~cm}^{-}}$ & $1420 \mathrm{~cm}^{-}$ & $1339 \mathrm{~cm}^{-}$ & $1319 \mathrm{~cm}^{-}$ & $600 \mathrm{~cm}$ \\
\hline D-BSA & 0.20 & 1.01 & 0.51 & 0.59 & 0.12 \\
\hline $\mathrm{D}-\mathrm{BSA}+\mathrm{Q} 2$ & 0.49 & 1.13 & 0.46 & 0.73 & 0.54 \\
\hline $\mathrm{D}-\mathrm{BSA}+\mathrm{Q} 6$ & 0.42 & 1.40 & N. D. & 0.69 & 0.49 \\
\hline $\begin{array}{l}\text { D-BSA + } \\
\text { Q10 }\end{array}$ & 1.15 & 1.32 & N. D. & 0.78 & 1.72 \\
\hline
\end{tabular}

Integrated intensity (peak intensity) relative to that of the phenylalanine band at $1002 \mathrm{~cm}^{-1}$. N. D. = not detected. The concentration of BSA was $1.5 \times$ $10^{-5} \mathrm{~mol} / \mathrm{L}$, and DMSO was kept at $10 \%$. Q2, Q6, and Q10 indicate concentrations of $Q$ at $3.0 \times 10^{-5}, 9.0 \times 10^{-5}$, and $15.0 \times 10^{-5} \mathrm{~mol} / \mathrm{L}$, respectively.

increase in the intensity of fluorescence, as well as a blue shift, was observed when the concentration of DMSO in the BSA and Lys systems was less than 70\% (Figures 13A and $\mathbf{A}^{\prime}$ ); this indicates that the microenvironment of $\operatorname{Trp}$ residues was more hydrophobic. In the case of $\mathrm{Mb}$, a slight increase in fluorescence intensity also occurred, but a red shift, rather than a blue one, was observed (Figure 13A"). This suggests that the Trp residues in $\mathrm{Mb}$ were more hydrophilic. These phenomena may have resulted from structural changes in the proteins. When the concentration of DMSO was increased to $70 \%$, a sharp increase in the fluorescence intensity in the Lys and Mb systems (Figures 13A' and A") was observed, indicating that the surface Trp residues were buried into the protein aggregates [39-41].

With the addition of $\mathrm{Q}$, fluorescence quenching was observed in D-BSA, D-Lys, and D-Mb; simultaneous slight blue shifts also occurred (Figures 13B, 13B', and 13B"). Quenching processes usually involve two modes, dynamic and static. Dynamic quenching occurs when the excited fluorophore experiences contact with an atom or molecule that can facilitate non-radiative transitions to the ground state, while static quenching implies either the existence of a spherical region of effective quenching, or the formation of a ground-state non-fluorescent complex. In many cases, the fluorophore can be quenched both by collision and by complex formation with the same quencher $[42,43]$. The binding of $\mathrm{Q}$ with BSA, Lys, or Mb was static, as Q was less than $1.5 \times 10^{-5} \mathrm{~mol} / \mathrm{L}$. The mode was determined by comparing the fitting results of the dynamic, static, and the combination modes to the D-BSA-Q, D-Lys-Q, and

Table 5 Intensities ${ }^{a}$ of Raman Band in Lys

\begin{tabular}{llllll}
\hline & $\mathbf{1 6 1 1} \mathbf{~ c m}^{\mathbf{- 1}}$ & $\mathbf{1 5 0 0} \mathbf{~ c m}^{-1}$ & $\mathbf{1 3 1 9} \mathbf{~ c m}^{-1}$ & $\mathbf{7 5 8} \mathbf{~ c m}^{-1}$ & $\mathbf{6 0 0} \mathbf{~ c m}^{-\mathbf{1}}$ \\
\hline D-Lys & 0.13 & 0.09 & 0.12 & 0.77 & 0.01 \\
D-Lys+ Q2 & 1.00 & 0.10 & 0.82 & 0.74 & 0.74 \\
D-Lys+ Q6 & 1.51 & 0.18 & 1.25 & 0.27 & 1.09 \\
D-Lys+ Q10 & 1.83 & 0.47 & 1.56 & 0.22 & 1.40 \\
\hline
\end{tabular}

${ }^{a}$ Integrated intensity (peak intensity) relative to that of the phenylalanine band at $1008 \mathrm{~cm}^{-1}$. The concentration of Lys was $1.5 \times 10^{-5} \mathrm{~mol} / \mathrm{L}$, and DMSO was kept at $10 \%$. Q2, Q6, and Q10 indicate concentrations of Q at $3.0 \times 10^{-5}$, $9.0 \times 10^{-5}$, and $15.0 \times 10^{-5} \mathrm{~mol} / \mathrm{L}$, respectively.

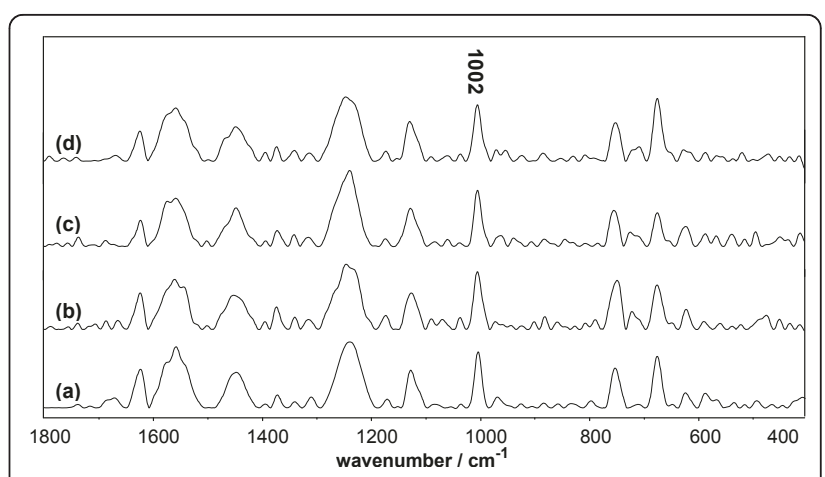

Figure 12 Raman spectrum of $\mathrm{Mb}$ system vs. the concentration of $\mathbf{Q}$. The concentrations of $\mathrm{Mb}$ and $\mathrm{DMSO}$ were maintained at 1.5 $\times 10^{-5} \mathrm{~mol} / \mathrm{L}$ and $10 \%$, respectively. (a) $0 \mathrm{~mol} / \mathrm{L} \mathrm{Q}$; (b) $3.0 \times 10^{-5}$ $\mathrm{mol} / \mathrm{L} \mathrm{Q}$; (c) $9.0 \times 10^{-5} \mathrm{~mol} / \mathrm{L} \mathrm{Q}$; (d) $1.5 \times 10^{-4} \mathrm{~mol} / \mathrm{L} \mathrm{Q}$.

D-Mb-Q systems (See Additional File 1: Fitting results of the different modes on the experimental data). In this case, the binding constant $\left(K_{a}\right)$ is equivalent to the quenching constant, which was determined by fitting Eq. $\mathbf{1}$ to the experimental data.

$$
\frac{F_{0}}{F}=1+K_{a}[Q]
$$

Where $F_{O}$ and $F$ represent the fluorescence intensities without and with the ligands, respectively; $K_{a}$ is defined

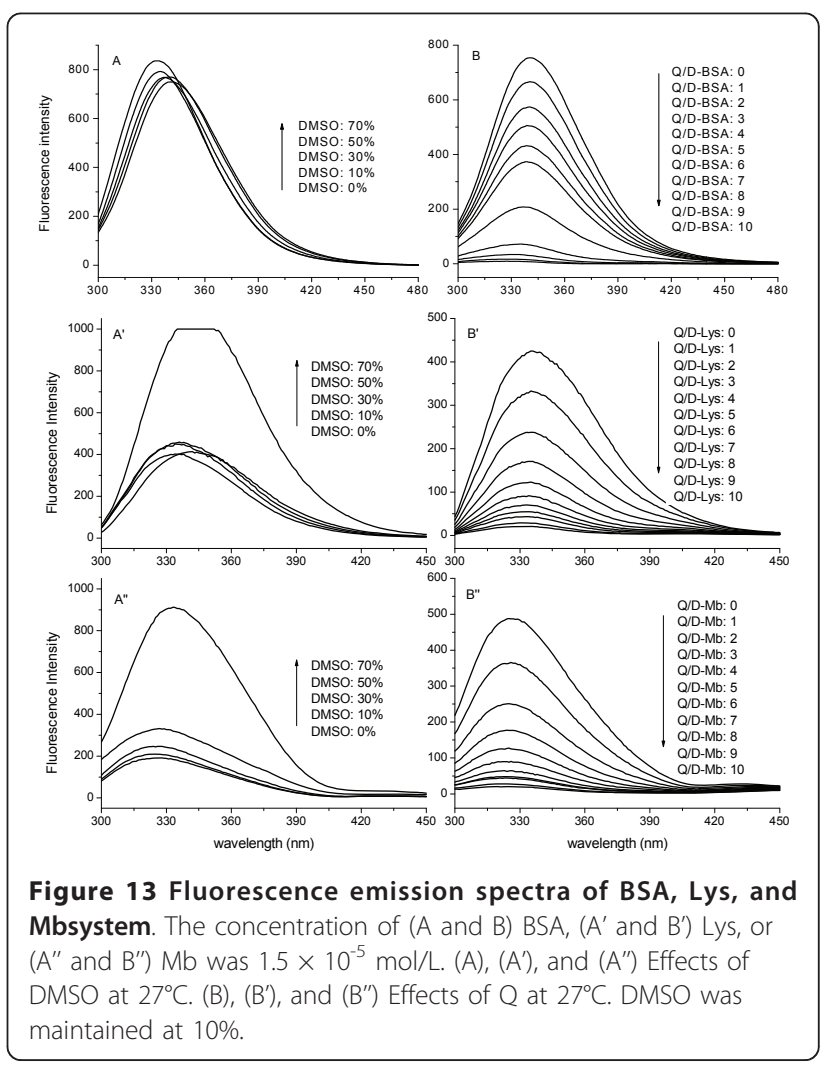


as the binding constant; and [Q] is the concentration of $\mathrm{Q}$. When the concentration of $\mathrm{Q}$ is very low, the binding constant $K_{a}$, which is equivalent to the equilibrium constant $K$, was calculated at certain experimental temperatures $\left(27\right.$ and $\left.37^{\circ} \mathrm{C}\right)$. The variation of the binding enthalpy $\Delta H$, which was assumed to not change with the temperature, was calculated usingthe classical Van't Hoff equation (Eq. 2):

$$
\ln \left(\frac{K_{2}}{K_{1}}\right)=-\frac{\Delta H}{R}\left(\frac{1}{T_{2}}-\frac{1}{T_{1}}\right)
$$

Where $T$ is the temperature and $R$ the ideal gas constant. The binding free energy $\Delta G$ was calculated using Eq. 3:

$$
\begin{aligned}
& \Delta G=-R T \ln K \\
& \Delta G=\Delta H-T \Delta S
\end{aligned}
$$

The variation of the binding entropy $\Delta S$ was calculated with Eq. 4, and the results are summarized in Table 6 [44-46].

The negative $\Delta G$ indicates that the binding of $\mathrm{Q}$ and Trp was energetically favourable. The positive $\Delta S$ and $\Delta H$ indicates that the binding reactions increased the entropy of the molecular environment of Trp, and were endothermic. This kind of reaction is typically hydrophobic [47]. Six Trp residues are contained in one Lys polypeptide backbone, but only two are contained in BSA or Mb. Although the precise binding location of each Q molecule is yet unknown, the lower entropy values of the BSA and Mb systems indicate that the distribution of $\mathrm{Q}$ around Trp residues was more convergent. The higher entropy in the Lys system indicates that the distribution of $\mathrm{Q}$ was more scattered, caused perhaps by too many Trp residues. This understanding is illustrated in Figure 14.

\section{UV-Vis Spectroscopy}

Figure 15 compares the UV-Vis absorption spectra of $\mathrm{Q}$, D-BSA-Q (A), D-BSA-Q (B), and D-Mb-Q (C). The pure $Q$ showed its characteristic band at $367 \mathrm{~nm}$, which is associated with the cinnamoyl group [16]. Normally,

Table $\mathbf{6}$ Binding parameters between $\mathbf{Q}$ and the three
proteins
\begin{tabular}{llllll}
\hline Pro. & Temp. $\left({ }^{\circ} \mathrm{C}\right)$ & $\boldsymbol{K}_{\boldsymbol{a}}(\mathrm{L} / \mathrm{mol})$ & $\boldsymbol{\Delta G}(\mathbf{k J} / \mathbf{m o l})$ & $\boldsymbol{\Delta} \mathbf{H ~}(\mathbf{k J} / \mathbf{m o l})$ & $\Delta \mathbf{S ~}(\mathrm{J} / \mathbf{m o l} \cdot \mathbf{K})$ \\
\hline BSA & 27 & $7.34 \times 10^{4}$ & -27.94 & 5.88 & 112.80 \\
& 37 & $7.92 \times 10^{4}$ & -29.07 & & \\
Lys & 27 & $2.93 \times 10^{4}$ & -25.65 & 12.40 & 126.90 \\
& 37 & $3.44 \times 10^{4}$ & -26.92 & & \\
Mb & 27 & $3.72 \times 10^{4}$ & -26.25 & 8.08 & 114.50 \\
& 37 & $4.13 \times 10^{4}$ & -27.39 & & \\
\hline
\end{tabular}

the formation of $\mathrm{H}$-bonds between the chromophoric group of $\mathrm{Q}$ and auxochromic group can result in an obvious red shift [48-50]; this was found when $Q$ was mixed with BSA (A). No shift of this band was found when $\mathrm{Q}$ was mixed with Lys $(\mathbf{B})$ or $\mathrm{Mb}(\mathbf{C})$, indicating no $\mathrm{H}$-bonds formed between $\mathrm{Q}$ and the two proteins. Thus, the quantity of $\mathrm{Q}$ bound to Lys and Mb was probably less than that bound to BSA.

\section{Binding and Release Capacity of Proteins}

Figure 16 compares the Q binding capacities of BSA, Lys, and $\mathrm{Mb}$ molecules by means of salting-out. The quantities of the bound $\mathrm{Q}$ increased with increasing ratio of $\mathrm{Q}$ and protein $(\mathrm{Q} / \mathrm{D}$-Pro), reaching saturated values (7 for Lys, 9 for $\mathrm{Mb}$, and 11 for BSA) at Q/D-Pro ratios exceeding 16 . Thus, one Lys molecule could bind 7 Q molecules, one Mb molecule could bind 9, and one BSA molecule could bind 11 . The binding capacity of BSA was confirmed to be the highest. Obviously, $\mathrm{H}$ bonds contributed to the enhanced binding capacity of BSA. In addition, the higher molecular weight (MW) of BSA increased the possibility of surface contact between the protein and Q and favored the hydrophobic effects.

Figure 17 compares the quantity of oxidized $\mathrm{Q}$ in the system, without or with proteins, in acidic and neutral conditions (A), and shows the enlarged part of the curves at $\mathrm{pH} 7.4$ during the first $24 \mathrm{~h}$ of reaction (B). Q was rapidly auto-oxidized by $\mathrm{O}_{2}$ in water to form o-quinone/quinone methide [13,51-53]. Since only the free $\mathrm{Q}$ could be easily oxidized, the curves in Figure 17 are equivalent to the curves of the release capacity of the proteins. Q was relatively stable in acidic conditions, and no oxidation was observed during the first $96 \mathrm{~h}$ of the reaction. BSA, Lys, and Mb administration extended the steady state to $120 \mathrm{~h}$. In neutral conditions, Q became very unstable. In Figure 17B, more than $90 \%$ of the $\mathrm{Q}$ in the system without protein rapidly oxidized during the first $24 \mathrm{~h}$ of the reaction. Evidently, the kinetics of oxidation was greatly reduced by the BSA nanocarrier, i.e., less than $10 \%$ of the $\mathrm{Q}$ was oxidized during the first $24 \mathrm{~h}$ of reaction, and less than $70 \%$ of the $\mathrm{Q}$ was oxidized at $216 \mathrm{~h}$. This protection was not provided by the Lys and $\mathrm{Mb}$ nanocarriers.

\section{Antioxidant Activity of Quercetin}

DPPH and ABTS radical cation decolourization tests are spectrophotometric methods widely used to assess the antioxidant activity of various substances. Previous studies confirmed that $\mathrm{Q}$ has a high DPPH and ABTS antioxidant activity [54-56]. The present study compares the antioxidant activity of $\mathrm{Q}$ and embedded $\mathrm{Q}$ in BSA, Lys, and $\mathrm{Mb}$ nanocarriers. As shown in Figure 18A, the DPPH percent radical scavenging activity (\% RSC) of Q was $82 \%$, while the DPPH \% RSC of all embedded Q did 


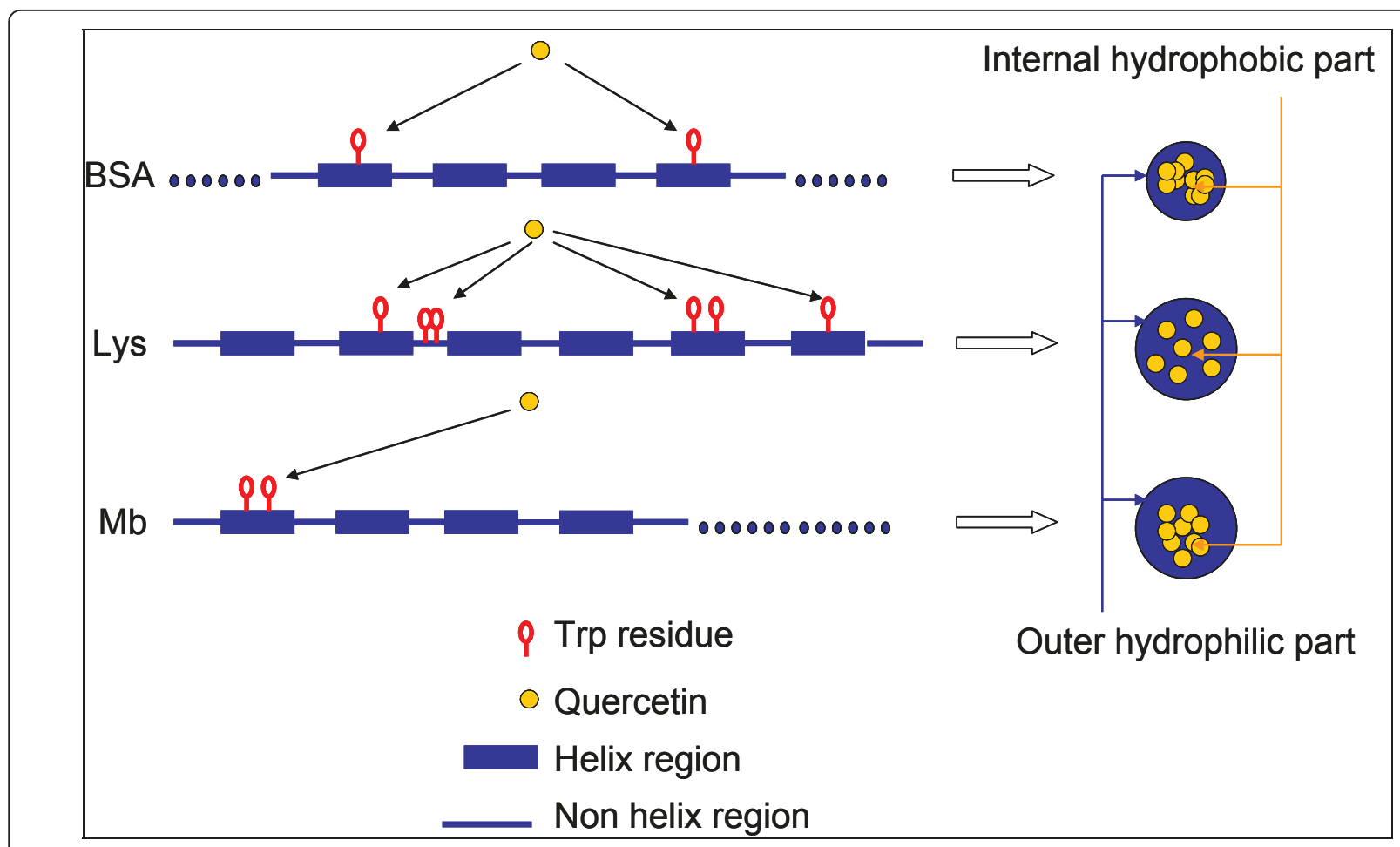

Figure 14 Schematic thermodynamics of binding $\mathbf{Q}$ on different proteins. Interpretation of the figure is provided in the text.

not change $(\mathrm{P}<0.05)$ at all. Likewise, the ABTS \% RSC of Q was $67.06 \%$, while the ABTS \% RSC of embedded $\mathrm{Q}$ in Lys and $\mathrm{Mb}$ nanocarriers did not change $(\mathrm{P}<$ 0.05); only the ABTS \% RSC of embedded Q in the BSA nanocarriers decreased $(\mathrm{P}<0.05)$ in comparison with free $\mathrm{Q}$. This decrease, however, was so slight that it could be ignored (Figure 18B). Thus, antioxidant activity of $\mathrm{Q}$ was not interfered by protein nanoparticles.

Comparing the results acquired from the BSA, Lys, and $\mathrm{Mb}$ systems, BSA exhibited the best functional features, such as loading, controlled release, and particularly antioxidant protection of active drugs. Other commercially available flavonoids, such as kaempferol and rutin, were also investigated in order to produce a more general statement and conclusive study of such bionanoparticles. Similar to Q, the thermodynamic, i.e., $\Delta G$, values of kaempferol and rutin were negative (both about $-30 \mathrm{~kJ} / \mathrm{mol}$ ), and their $\Delta H$ and $\Delta S$ were positive (about $6 \mathrm{~kJ} / \mathrm{mol}$ and $113 \mathrm{~J} / \mathrm{mol} \cdot \mathrm{K}$ for kaempferol, $13 \mathrm{~kJ} / \mathrm{mol}$ and $130 \mathrm{~J} / \mathrm{mol} \cdot \mathrm{K}$ for rutin, respectively), indicating that these substances could be hydrophobically loaded by BSA since the size of the bionanosystem is less than $30 \mathrm{~nm}$. One BSA could bind 12 kaempferl molecules and 5 rutin molecules. The main features of the oxidation kinetics of
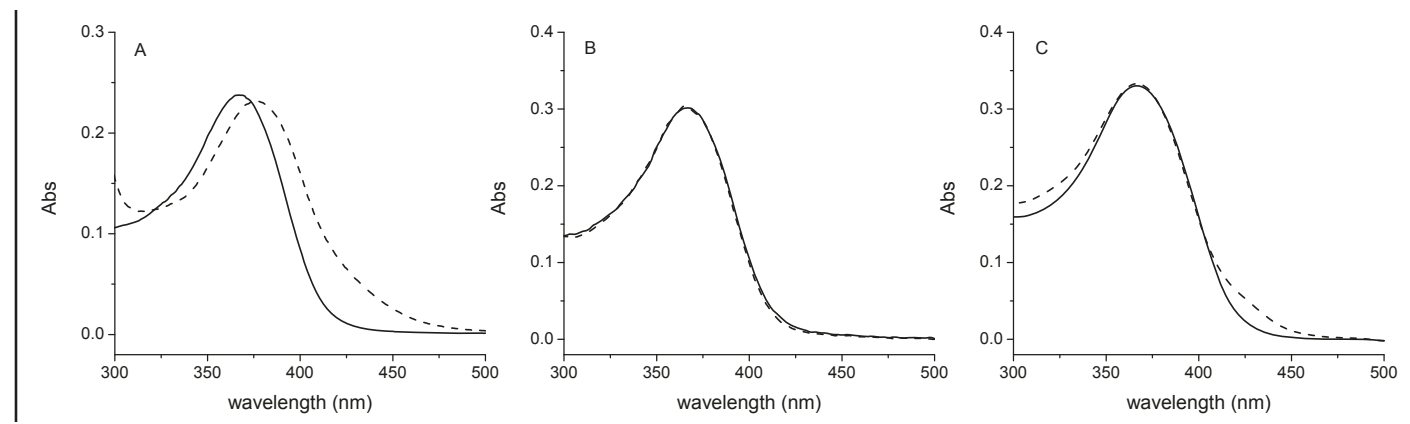

Figure 15 UV-Vis spectra of free and bound Q to D-BSA, D-Lys, and D-Mb. The concentration of Q was $1.5 \times 10^{-5}$ mol/L. The concentration of DMSO was maintained at 10\%. The concentration of (A) BSA, (B) Lys, or (C) Mb was $1.5 \times 10^{-5} \mathrm{~mol} / \mathrm{L}$. The solid line represents free $\mathrm{Q}$, and the dashed line represents bound $\mathrm{Q}$. 


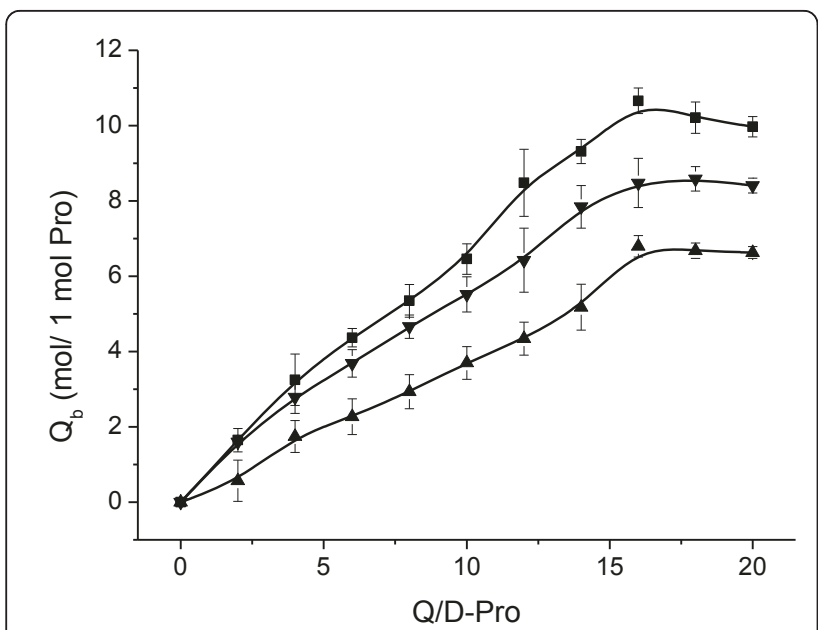

Figure 16 The $Q$ binding capacities of $B S A$, Lys, and Mb. $Q_{b}$ represents the quantity of $\mathrm{Q}$ bound to protein molecule. The concentration of BSA, Lys, or Mb was all maintained at $1.5 \times 10^{-5}$ $\mathrm{mol} / \mathrm{L}$, and the concentration of DMSO was maintained at $10 \%$. Black square refers to BSA NP; black upper triangle refers to Lys NP; black lower triangle refers to Mb NP.

kaempferol and rutin in the BSA system were very similar to those of $\mathrm{Q}$ under the same conditions.

\section{Conclusions}

In this work, we demonstrated that proteins, such as BSA, Lys, and Mb be used to fabricate bioactive nanoparticles resulting from the secondary and tertiary

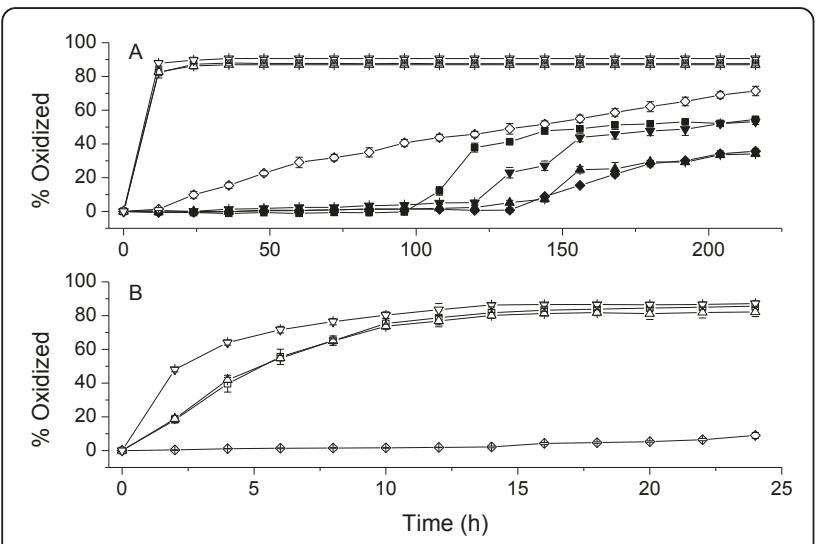

Figure 17 Comparison of the quantity of the oxidized $Q$ in the system without or with protein. The concentrations of $Q$ and protein (BSA, Lys, and Mb) were $1.5 \times 10^{-4}$ and $1.5 \times 10^{-5} \mathrm{~mol} / \mathrm{L}$, respectively. Q solution was prepared with $10 \%$ DMSO. (A) Measurements during 216 hours. (B) Measurements during the first 24 hours at $\mathrm{pH}$ 7.4. Black square refers to $\mathrm{Q}$ without protein at $\mathrm{pH}$ 1.2; balck rhombus refers to $\mathrm{Q}$ with $\mathrm{BSA}$ at $\mathrm{pH}$ 1.2; black upper triangle refers to $\mathrm{Q}$ with $\mathrm{Lys}$ at $\mathrm{pH} 1.2$; black lower triangle refers to $\mathrm{Q}$ with $\mathrm{Mb}$ at $\mathrm{pH}$ 1.2; white square refers to $\mathrm{Q}$ without protein at $\mathrm{pH} 7.4$; white rhombus refers to $\mathrm{Q}$ with $\mathrm{BSA}$ at $\mathrm{pH} 7.4$; white upper triangle refers to $\mathrm{Q}$ with $\mathrm{Lys}$ at $\mathrm{pH}$ 7.4; white lower triangle refers to $\mathrm{Q}$ with $\mathrm{Mb}$ at $\mathrm{pH}$ 7.4.

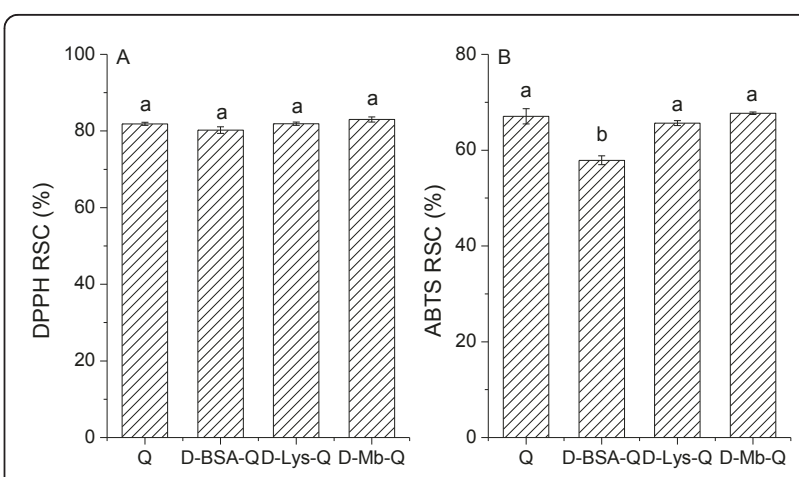

Figure $18 \mathrm{DPPH}$ and $\mathrm{ABTS}$ scavenging activity of $\mathrm{Q}$ and embedded $\mathbf{Q}$. The concentrations of $\mathrm{Q}$ was $1.50 \times 10^{-5} \mathrm{~mol} / \mathrm{L}$. The concentration of the proteins (BSA, Lys, and Mb) was $1.5 \times 10^{-6}$ $\mathrm{mol} / \mathrm{L}$. The (A) DPPH and (B) ABTS scavenging activities of the proteins were also subtracted from the embedded Q. Markers of different letters in the figure denote that the mean difference is significant at $P<0.05$.

structure transformations promoted by DMSO to deliver hydrophobic drugs such as Q. The adsorption of Q on proteins was mainly hydrophobic, particularly occurring in the region of Trp residues. BSA exhibited the highest binding capacity of $\mathrm{Q}$, indicating that $\mathrm{H}$-bonding and MWs also contribute to enhancing binding capacity. The formation of a hydrophobic core surrounded by a hydrophilic outer layer was therefore promoted. Protein nanocarriers can not only transport $Q$ molecules, they also provide a protective effect on the activity of $Q$ in both acidic and neutral conditions. The antioxidant activity of $\mathrm{Q}$ was also preserved by entrapment by the nanocarrier. Through the formation of complex aggregates composed of proteins, especially the BSA system, DMSO, and Q, such bio-nanoparticles with improved properties could be potentially efficient drug-carriers. Confirmed by further studies on kaempferol and rutin, this approach of protein nanoparticle preparation may provide a general and conclusive way to deliver hydrophobic drugs.

\section{Methods \\ Materials}

BSA (Fraction V) (A-0332) was purchased from AMRESCO (Amresco Inc., OH, USA); its MW was 67, $200 \mathrm{Da}$, and its purity was 98\%. Myoglobin (Mb, M0630) was purchased from Sigma Aldrich, Inc. (St. Louis, MO, USA); its MW was 17, 800, and its purity was > 95\%. Lysozyme (Lys) was purchased from Sanland Chemical Co. (LTD, LA, USA); its MW was 14, $400 \mathrm{Da}$. The isoelectric point (pI) of Lys in this work was about 7.0 as determined by zeta potential measurements. The stock solutions of BSA, Lys, and Mb $\left(1.5 \times 10^{-3} \mathrm{~mol} / \mathrm{L}\right)$ were prepared with Milli-Q water and stored in the refrigerator at $4^{\circ} \mathrm{C}$ prior to use. 1-Diphenyl-2-picrylhydrazyl 
(DPPH, D9132-1G), 2,2'-azinobis (3-ethylbenzothiazoline-6-sulfonic acid) diammonium salt (ABTS, A-1888), and dimethyl sulfoxide (DMSO) were all purchased from Sigma Aldrich, Inc. (St. Louis, MO, USA). The purity of DMSO was 99.5\%. Quercetin (3,3',4',5,7-pentahydroxyflavone hydrate, Q-100081) was purchased from the National Institute for the Control of Pharmaceutical and Biological Products (Beijing, China); its purity was 97.3\%, as detected by high performance liquid chromatography. The stock solution of Q $\left(1.5 \times 10^{-3} \mathrm{~mol} / \mathrm{L}\right)$ was prepared with DMSO, and stored in the refrigerator at $4^{\circ} \mathrm{C}$ prior to use. All other reagents used were of analytical grade or purer.

\section{Preparation of DMSO-inducing protein nanoparticle (D- BSA, D-Lys, and D-Mb)}

BSA, Lys, and Mb stock solutions $\left(1.5 \times 10^{-3} \mathrm{~mol} / \mathrm{L}\right)$ were diluted to $1.5 \times 10^{-5} \mathrm{~mol} / \mathrm{L}$; various volumes of DMSO were added. The total volume of the solution was kept at $10 \mathrm{~mL}$, and the concentrations of DMSO were $1 \%, 10 \%$, $20 \%, 30 \%, 40 \%, 50 \%, 60 \%$, and $70 \%$. The solution was mixed thoroughly for $5 \mathrm{~min}$. Freeze-drying was used to remove DMSO [57] and obtain the nanoparticles.

Preparation of Quercetin-loaded protein nanoparticle (DBSA-Q, D-Lys-Q, and D-Mb-Q)

BSA, Lys, and Mb stock solutions $\left(1.5 \times 10^{-3} \mathrm{~mol} / \mathrm{L}\right)$ were diluted to $1.5 \times 10^{-5} \mathrm{~mol} / \mathrm{L}$, and various volumes of $\mathrm{Q}$ were added. The total volume of the solution was kept at $10 \mathrm{~mL}$, and the concentration of DMSO was kept at $10 \%$; the concentration of $\mathrm{Q}$ was adjusted from $1.5 \times 10^{-5}$ to $1.5 \times 10^{-4} \mathrm{~mol} / \mathrm{L}$. The solution was mixed thoroughly for $5 \mathrm{~min}$. Freeze-drying was used to remove DMSO [57] and obtain the nanoparticles.

\section{Scanning Transmission Electron Microscopy (STEM)}

Ten microliter samples were deposited onto a copper TEM grid for $5 \mathrm{~s}$, after which the excess solutions were absorbed. Phosphotungstic acid was used to stain the sample. The observations were performed with a HITACHIS-5500 STEM (Hitachi High-Technologies America, Inc. IL, USA) at $30 \mathrm{KV}$. Images $(1280 \times 960$ pixels $)$ were acquired using a Gatan high-angle annular bright field (HAABF) scintillating detector.

\section{Dynamic Light Scattering (DLS) Measurements}

Hydrodynamic sizes and zeta potentials were determined by means of photon correlation spectroscopy using a Delsa Nano Particle Analyzer (A53878, Beckman Coulter, Inc., CA, USA). The size measurements were performed at $25^{\circ} \mathrm{C}$ and at a $15^{\circ}$ scattering angle. Size was recorded for $400 \mu \mathrm{s}$ for each measurement, and the accumulation time was 3 times. In dynamic light scattering, when the hydrodynamic size was measured, the fluctuations in the time of scattered light from particles in Brownian motion were measured. The zeta potential measurements were performed at $25^{\circ} \mathrm{C}$. The accumulation time was 70 times, and equilibration time was $60 \mathrm{sec}$.

\section{Raman Spectroscopy Measurements}

The solution samples were prepared as in the section on sample preparation. Raman spectral data were collected with a HORIBA Jobin Yvon HR800 spectrometer (HORIBA Jobin Yvon S.A.S., Villeneuve Dáscq, France), with $785 \mathrm{~nm}$ excitation. Spectral differences were recorded in the $400-2000 \mathrm{~cm}^{-1}$ wave-number range. To increase the signal-to-noise ratio, at least 10 scans of each sample were collected to obtain averaged spectral data. The averaged spectral were baseline-corrected, and smoothed using ORIGIN software (version 8.0). The relative intensities were normalized to the phenylalanine band at 1002 or $1008 \mathrm{~cm}^{-1}$.

\section{Fluorescence Spectrometry Measurements}

The fluorescence intensities were recorded with a Cary Eclipse fluorophotometer (Varian, Inc., CA, USA). The widths of the excitation and emission slits of BSA, Lys, and $\mathrm{Mb}$ were set to 2.5/5.0, 5.0/5.0, and 10.0/20.0 nm, respectively. All the operations were carried out at 27 and $37^{\circ} \mathrm{C}$. Fluorescence spectra were then measured in the range of 200-500 $\mathrm{nm}$ at an excitation wavelength of $280 \mathrm{~nm}$. Each spectrum was background-corrected by subtracting the spectrum of the Milli-Q water and DMSO blank.

\section{UV-Vis Spectrometry Measurements}

All the samples were scanned on a Varian Cary 50 UVvisible spectrophotometer (Varian Medical Systems, Inc., CA, USA) at wavelength range of 300-500 $\mathrm{nm}$. The operations were carried out at room temperature, $25^{\circ} \mathrm{C}$. The scan rate was $600.00 \mathrm{~nm} / \mathrm{min}$. The data interval was $1.00 \mathrm{~nm}$, and the average time was $0.10 \mathrm{sec}$. All the absorptions of the protein (BSA, Lys, and Mb) were near $280 \mathrm{~nm}$. In the case of $\mathrm{Mb}$, another weak absorption appeared at $420 \mathrm{~nm}$.

\section{Determination of Quercetin Loading Capacity (Salting Out Analysis)}

The Q entrapped by nanocarriers was separated from the free $\mathrm{Q}$ through the salting out method as described below. A $5 \mathrm{~mL}$ sample was placed in a beaker. Excess ammonium sulphate was added to the beaker, and the mixture was stirred for $10 \mathrm{~min}$ and then left to stand for $20 \mathrm{~min}$. A $2 \mathrm{~mL}$ solution was transferred to a centrifuge tube, and then centrifuged for $30 \mathrm{~min}$ at 15,000 $\mathrm{rpm}$, at $4^{\circ} \mathrm{C}$. The absorbance (Abs) of free $\mathrm{Q}$ in supernatant was detected at $367 \mathrm{~nm}$ by a Varian Cary 50 UVVis spectrophotometer (Varian Medical Systems, Inc., 
CA, USA), and the concentration of free Q was calculated by the standard curve method. The entrapped $\mathrm{Q}$ was calculated by determining all the $\mathrm{Q}$ in a sample and then subtracting the free $\mathrm{Q}$. All measurements were performed in triplicate.

\section{Quercetin Stability and Release Study In Vitro (UV-Vis Spectrometry Analysis)}

The $\mathrm{pH}$ conditions of the release buffer were controlled using phosphate buffer ( $\mathrm{pH}$ 7.4) or $\mathrm{HCl}(\mathrm{pH}$ 1.2). The experiment was carried out using an improved method of Arnedo [8] as described below. A $90 \mathrm{~mL}$ sample was separated into 30 tubes, placed in an incubator at $37^{\circ} \mathrm{C}$, and then wagged at $100 \mathrm{rpm}$. The tubes were successively detected at predetermined intervals by means of UV-Vis spectrometry. All measurements were performed in triplicate.

\section{Antioxidant Activity Evaluation DPPH Assay}

The DPPH assay was used to evaluate the free radical scavenging activity on the DPPH • of each sample. When $\mathrm{DPPH}$ - reacted with an antioxidant compound, the DPPH was reduced. The change in color was measured at $517 \mathrm{~nm}$. The DPPH free radical scavenging activity was determined by the method of Hao [58]. Stock solutions of DPPH were prepared at $2.5 \mathrm{mmol} / \mathrm{L}$, and then diluted to $0.15 \mathrm{mmol} / \mathrm{L}$. Each sample $(15 \mu \mathrm{L})$ was mixed with $0.05 \mathrm{~mol} / \mathrm{L}(\mathrm{pH} 7.4)$ of Tris- $\mathrm{HCl}$ buffer $(60 \mu \mathrm{L})$ and $0.15 \mathrm{mmol} / \mathrm{L}$ DPPH working solution $(150 \mu \mathrm{L})$ in a 96 well plate. The mixture was shaken vigorously, and then left to stand for $30 \mathrm{~min}$ in the dark. The absorbance $\left(A_{\text {Sample }}\right)$ at $517 \mathrm{~nm}$ was recorded using a microplate reader (Model 680, Bio-Rad Laboratories, Inc., CA, USA). All the samples were analyzed in triplicate. The absorbance of the control $\left(A_{\text {Control }}\right)$ was obtained by replacing the sample with ethanol. The percent radical scavenging activity (\% RSC) was calculated using the formula shown below:

$$
\% \text { RSC }=\left[\left(A_{\text {Control }}-A_{\text {Sample }}\right) / A_{\text {Control }}\right] \times 100 \%
$$

\section{ABTS Assay}

The ABTS radical cation decolorization test is a spectrophotometric method widely used for the assessment of antioxidant activity of various substances. The experiment was carried out by the method of Re [59]. In brief, $140 \mathrm{mmol} / \mathrm{L}$ ABTS stock solution was diluted in water to a concentration of $14 \mathrm{mM}$. A mixture of $500 \mu \mathrm{L} 14$ mM ABTS diluent and $500 \mu \mathrm{L} 4.9 \mathrm{mM}$ potassium persulfate (KPS) stock solution was placed in a $1.5 \mathrm{~mL}$ tube, and then left to stand in the dark at room temperature for at least $12 \mathrm{~h}$ before use. To study the samples, the ABTS. solution was diluted with the sample buffer to an absorbance of $0.70 \pm 0.02$ at $734 \mathrm{~nm}$. After the addition of $900 \mu \mathrm{L}$ of diluted ABTS solution to $100 \mu \mathrm{L}$ of sample, the absorbance $\left(A_{\text {Sample }}\right)$ reading was taken after exactly $4 \mathrm{~min}$. A sample buffer blank $\left(A_{\text {Control }}\right)$ was run in each assay. All determinations were carried out in triplicate. The percent radical scavenging activity (\% RSC) was calculated using Eq. 5.

\section{Additional material}

Additional file 1: Fitting results of the different modes on the experimental data. The concentration of BSA (A and $\mathbf{B})$, Lys $\left(\mathbf{A}^{\prime}\right.$ and $\left.\mathbf{B}^{\prime}\right)$, or $\mathrm{Mb}\left(\mathbf{A}^{\prime \prime}\right.$ and $\left.\mathbf{B}^{\prime \prime}\right)$ were $1.5 \times 10^{-5} \mathrm{~mol} / \mathrm{L}$. $(\mathbf{A}),\left(\mathbf{A}^{\prime}\right)$, and $\left(\mathbf{A}^{\prime \prime}\right)$ Comparison of the fitting results of the dynamic, static and simultaneous modes at $27^{\circ} \mathrm{C}$. The concentration of $\mathrm{Q}$ varied from 0 to $1.2 \times 10^{-5} \mathrm{~mol} / \mathrm{L}$. Black square refers to experimental data; dot line refers to the dynamic mode; dash line refers to the static mode; solid line refers to the simultaneous mode. (B), $\left(\mathbf{B}^{\prime}\right)$, and $\left(\mathbf{B}^{\prime \prime}\right)$ Comparison of the fitting results at 27 and $37^{\circ} \mathrm{C}$. Black square refers to $27^{\circ} \mathrm{C}$ and black round refers to $37^{\circ} \mathrm{C}$.

\section{Acknowledgements}

This research was supported by the National Scienceand Technology Support Program (No. 2011BAD23B04). Prof. Yunjie Yan (Beijing National Center for Electron Microscopy, Department of Materials Science and Engineering, Tsinghua University), Prof. Wei Qi (Chemical Engineering Research Center, School of Chemical Engingeering and Technology, Tianjin University, Tianjin, China), Engr. Ke Zhu (Institute of Physics, Chinese Academy of Sciences, Beijing, China), and Dr. Yanhong Liu (Technical Institute of Physics and Chemistry, Chinese Academy of Sciences, Beijing, China) are acknowledged for their technical advice.

\section{Author details}

${ }^{1} \mathrm{CAU}$ and ACC Joint Laboratory of Space Food, College of Food Science and Nutritional Engineering, China Agricultural University, Key Laboratory of Functional Dairy Science of Beijing and the Ministry of Education, Beijing Higher Institution Engineering Research Center of Animal Product, No.17 Qinghua East Road, Haidian, Beijing 100083, China. ${ }^{2}$ Groupe de PhysicoChimie de L'Environnement, Institut Forel, Section des Sciences de la Terre et de l'Environnement, Université de Genève, 10, route de Suisse, CH-1290 Versoix, Switzerland.

\section{Authors' contributions}

$X J, H J$, and RF coordinated the experiments, and provided important advice for each. RF performed the majority of the experiments and characterization. ZC, SS, GHZ, FZR, and FL participated in the characterization. All authors read, participated in writing, and approved of the final manuscript.

\section{Competing interests}

The authors declare that they have no competing interests.

Received: 27 January 2011 Accepted: 17 May 2011

Published: 17 May 2011

\section{References}

1. Lewinski N, Colvin V, Drezek R: Cytotoxicity of nanoparticles. Small 2008, 4:26-49.

2. Liu J, Huang W, Pang Y, Zhu $X$, Zhou $Y$, Yan D: The in vitro biocompatibility of self-assembled hyperbranched copolyphosphate nanocarriers. Biomaterials 2010, 31:5643-5651.

3. Shieh M, Peng C, Chiang W, Wang C, Hsu C, Wang S, Lai P: Reduced Skin Photosensitivity with meta-Tetra (hydroxyphenyl) chlorin-Loaded Micelles Based on a Poly (2-ethyl-2-oxazoline)-b-poly (d, l-lactide) Diblock Copolymer in Vivo. Mol Pharm 2010, 7:1244-1253. 
4. Li Y, Xiao K, Luo J, Lee J, Pan S, Lam K: A novel size-tunable nanocarrier system for targeted anticancer drug delivery. I Control Release 2010, 144:314-323.

5. MaHam A, Tang Z, Wu H, Wang J, Lin Y: Protein-based nanomedicine platforms for drug delivery. Small 2009, 5:1706-1721.

6. Wang $G$, Uludag H: Recent developments in nanoparticle-based drug delivery and targeting systems with emphasis on protein-based nanoparticles. Expert Opin Drug Deliv 2008, 5:499-515.

7. Jahanshahi M, Najafpour G, Rahimnejad M: Applying the Taguchi method for optimized fabrication of bovine serum albumin (BSA) nanoparticles as drug delivery vehicles. Afr J Biotechnol 2008, 7:362-367.

8. Arnedo A, Espuelas S, Irache J: Albumin nanoparticles as carriers for a phosphodiester oligonucleotide. Int J Pharm 2002, 244:59-72.

9. Maghsoudi A, Shojaosadati S, Vasheghani Farahani E: 5-Fluorouracil-Loaded BSA Nanoparticles: Formulation Optimization and In Vitro Release Study. AAPS Pharm Sci Tech 2008, 9:1092-1096.

10. Ascenzi P, Bocedi A, Notari S, Fanali G, Fesce R, Fasano M: Allosteric modulation of drug binding to human serum albumin. Mini Rev Med Chem 2006, 6:483-489.

11. Ascoli $G$, Domenici $E$, Bertucci C: Drug binding to human serum albumin: Abridged review of results obtained with high-performance liquid chromatography and circular dichroism. Chirality 2006, 18:667-679.

12. Di Carlo G, Mascolo N, lzzo A, Capasso F: Flavonoids: old and new aspects of a class of natural therapeutic drugs. Life Sci 1999, 65:337-353.

13. van der Woude H, Gliszczyska-wigo A, Struijs K, Smeets A, Alink G, Rietjens I: Biphasic modulation of cell proliferation by quercetin at concentrations physiologically relevant in humans. Cancer lett 2003, 200:41-47.

14. Bhattacharjya S, Balaram P: Effects of organic solvents on protein structures: observation of a structured helical core in hen egg-white lysozyme in aqueous dimethylsulfoxide. Proteins 1997, 29:492-507.

15. Dufour C, Dangles O: Flavonoid-serum albumin complexation: determination of binding constants and binding sites by fluorescence spectroscopy. Biochim Biophys Acta 2005, 1721:164-173.

16. Ni Y, Zhang $X$, Kokot S: Spectrometric and voltammetric studies of the interaction between quercetin and bovine serum albumin using warfarin as site marker with the aid of chemometrics. Spectrochim Acta A Mol Biomol Spectrosc 2009, 71:1865-1872.

17. Fasano M, Curry S, Terreno E, Galliano M, Fanali G, Narciso P, Notari S, Ascenzi P: The extraordinary ligand binding properties of human serum albumin. IUBMB life 2005, 57:787-796.

18. Jóhannesson H, Denisov V, Halle B: Dimethyl sulfoxide binding to globular proteins: A nuclear magnetic relaxation dispersion study. Protein Sci 1997 6:1756-1763

19. Paramaguru $G$, Kathiravan $A$, Selvaraj $S$, Venuvanalingam $P$, Renganathan $R$ : Interaction of anthraquinone dyes with lysozyme: Evidences from spectroscopic and docking studies. J Hazard Mater 2009, 175:985-991.

20. Li D, Cao X, Ji B: Spectrophotometric studies on the interaction between myricetin and lysozyme in the absence and presence of $\mathrm{Cu}^{2+}$ or $\mathrm{Fe}^{3+} . J$ Lumin 2010, 130:1893-1900

21. lafisco M, Palazzo B, Falini G, Di Foggia M, Bonora S, Nicolis S, Casella L, Roveri N: Adsorption and conformational change of myoglobin on biomimetic hydroxyapatite nanocrystals functionalized with alendronate. Langmuir 2008, 24:4924-4930

22. Feng M, Tachikawa H: Raman spectroscopic and electrochemica characterization of myoglobin thin film: implication of the role of histidine 64 for fast heterogeneous electron transfer. J Am Chem Soc 2001, 123:3013-3020

23. Li Q, Mabrouk P: Spectroscopic and electrochemical studies of horse myoglobin in dimethyl sulfoxide. J Biol Inorg Chem 2003, 8:83-94.

24. Matsuda Y, Kobayashi M, Annaka M, Ishihara K, Takahara A: Dimensions of a free linear polymer and polymer immobilized on silica nanoparticles of a zwitterionic polymer in aqueous solutions with various ionic strengths. Langmuir 2008, 24:8772-8778.

25. Trirongjitmoah S, Sakurai T, linaga K, Chiba H, Shimizu K: Fraction estimation of small, dense LDL using autocorrelation function of dynamic light scattering. Opt Express 2010, 18:6315-6326.

26. Chen M, Lord R: Laser-excited Raman spectroscopy of biomolecules. VIII. Conformational study of bovine serum albumin. J Am Chem Soc 1976, 98:990-992.

27. Liang $\mathrm{M}$, Chen V, Chen $\mathrm{H}$, Chen W: A simple and direct isolation of whey components from raw milk by gel filtration chromatography and structural characterization by Fourier transform Raman spectroscopy. Talanta 2006, 69:1269-1277

28. Ou W, Wang R, Zhou H: Conformational changes and inactivation of rabbit muscle creatine kinase in dimethyl sulfoxide solutions. Biochem Cell Biol 2002, 80:427-434.

29. Jurasekova Z, Marconi G, Sanchez-Cortes S, Torreggiani A: Spectroscopic and molecular modeling studies on the binding of the flavonoid luteolin and human serum albumin. Biopolymers 2009, 91:917-927.

30. Aliaga A, Osorio-Román I, Leyton P, Garrido C, Cárcamo J, Caniulef C, Célis F, Díaz F: Surface-enhanced Raman scattering study of Ltryptophan. J Raman Spectrosc 2009, 40:164-169.

31. Zhao W, Yang R: Experimental Study on Conformational Changes of Lysozyme in Solution Induced by Pulsed Electric Field and Thermal Stresses. J Phys Chem B 2009, 114:503-510.

32. Mi kovsky $P$, Jancura $D$, Sánchez-Cortés $S$, Kociová E, Chinsky L: Antiretrovirally active drug hypericin binds the IIA subdomain of human serum albumin: Resonance Raman and surface-enhanced Raman spectroscopy study. J Am Chem Soc 1998, 120:6374-6379.

33. Miura T, Takeuchi H, Harada I: Raman spectroscopic characterization of tryptophan side chains in lysozyme bound to inhibitors: role of the hydrophobic box in the enzymic function. Biochemistry 1991, 30:6074-6080.

34. Miura T, Suzuki K, Takeuchi H: Binding of iron (III) to the single tyrosine residue of amyloid [beta]-peptide probed by Raman spectroscopy. J Mol Struct 2001, 598:79-84.

35. Badii F, Howell N: Fish gelatin: structure, gelling properties and interaction with egg albumen proteins. Food Hydrocolloid 2006, 20:630-640.

36. Lehninger A, Nelson D, Cox M: Lehninger principles of biochemistry. Wh Freeman 2005

37. Bellezza F, Cipiciani A, Latterini L, Posati T, Sassi P: Structure and Catalytic Behavior of Myoglobin Adsorbed onto Nanosized Hydrotalcites. Langmuir 2009, 25:10918-10924

38. Morgan C, Miranker A, Dobson C: Characterization of Collapsed States in the Early Stages of the Refolding of Hen Lysozyme. Biochemistry 1998, 37:8473-8480

39. Itzhaki L, Evans P, Dobson C, Radford S: Tertiary interactions in the folding pathway of hen lysozyme: kinetic studies using fluorescent probes. Biochemistry 1994, 33:5212-5220.

40. Ibrahim H, Higashiguchi S, Juneja L, Kim M, Yamamotos T: A structural phase of heat-denatured lysozyme with novel antimicrobial action. J Agric Food Chem 1996, 44:1416-1423.

41. Liu H, Yin P, He S, Sun Z, Tao Y, Huang Y, Zhuang H, Zhang G, Wei S: ATPinduced noncooperative thermal unfolding of hen lysozyme. Biochem Biophys Res Commun 2010, 397:598-602.

42. Lakowicz J: Principles of Fluorescence Spectroscopy. New York: Springer press; 2006.

43. Valeur B: Molecular Fluorescence: Principles and Applications. Weinheim: Wiley-Vch press; 2001.

44. Bai Z, Lodge T: Thermodynamics and Mechanism of the Block Copolymer Micelle Shuttle between Water and an lonic Liquid. J Phys Chem B 2009, 113:14151-14157.

45. Bansiwal A, Thakre D, Labhshetwar N, Meshram S, Rayalu S: Fluoride removal using lanthanum incorporated chitosan beads. Colloids Surf $B$ Biointerfaces 2009, 74:216-224

46. Subbaiah M, Vijaya Y, Kumar N, Reddy A, Krishnaiah A: Biosorption of nickel from aqueous solutions by Acacia leucocephala bark: Kinetics and equilibrium studies. Colloids Surf B Biointerfaces 2009, 74:260-265.

47. Ross $\mathrm{P}$, Subramanian $\mathrm{S}$ : Thermodynamics of protein association reactions: forces contributing to stability. Biochemistry 1981, 20:3096-3102.

48. Schenning A, Herrikhuyzen J, Jonkheijm P, Chen Z, Würthner F, Meijer E: Photoinduced Electron Transfer in Hydrogen-Bonded Oligo ( $p$ phenylene vinylene)- Perylene Bisimide Chiral Assemblies. J Am Chem Soc 2002, 124:10252-10253.

49. Bell T, Hext N: Supramolecular optical chemosensors for organic analytes Chem Soc Rev 2004, 33:589-598.

50. Würthner F, Chen Z, Hoeben F, Osswald P, You C, Jonkheijm P Herrikhuyzen J, Schenning A, van der Schoot P, Meijer E: Supramolecular $\mathrm{p}$ - $\mathrm{n}$-Heterojunctions by Co-Self-Organization of Oligo ( $\mathrm{p}$-phenylene Vinylene) and Perylene Bisimide Dyes. J Am Chem Soc 2004, 126:10611-10618. 
51. Zheng Y, Haworth I, Zuo Z, Chow M, Chow A: Physicochemical and structural characterization of Quercetin- $\beta$-Cyclodextrin Complexes. J Pharm Sci 2005, 94:1079-1089.

52. Makris $\mathrm{D}$, Rossiter J: Heat-induced, metal-catalyzed oxidative degradation of quercetin and rutin (quercetin 3-O-rhamnosylglucoside) in aqueous model systems. J Agric Food Chem 2000, 48:3830-3838

53. Bermúdez-Soto M, Tomás-Barberán F, García-Conesa M: Stability of polyphenols in chokeberry (Aronia melanocarpa) subjected to in vitro gastric and pancreatic digestion. Food Chem 2007, 102:865-874.

54. Zhang J, Melton L, Adaim A, Skinner M: Cytoprotective effects of polyphenolics on $\mathrm{H}_{2} \mathrm{O}_{2}$-induced cell death in $\mathrm{SH}-\mathrm{SY} 5 \mathrm{Y}$ cells in relation to their antioxidant activities. Eur Food Res Technol A 2008, 228:123-131.

55. Ozgen M, Reese R, Tulio A Jr, Scheerens J, Miller A: Modified 2, 2-Azinobis-3-ethylbenzothiazoline-6-sulfonic Acid (ABTS) Method to Measure Antioxidant Capacity of Selected Small Fruits and Comparison to Ferric Reducing Antioxidant Power (FRAP) and 2, 2'-Diphenyl-1-picrylhydrazyl (DPPH) Methods. J Agric Food Chem 2006, 54:1151-1157.

56. Kang W, Wang J: In vitro antioxidant properties and in vivo lowering blood lipid of Forsythiasuspense leaves. Med Chem Res 2009, 19:617-628.

57. Pezeshki A, Vergote V, Van Dorpe S, Baert B, Burvenich C, Popkov A, De Spiegeleer B: Adsorption of peptides at the sample drying step: influence of solvent evaporation technique, vial material and solution additive. J Pharm Biomed Anal 2009, 49:607-612.

58. Jing H, Kitts D: Antioxidant activity of sugar-lysine Maillard reaction products in cell free and cell culture systems. Arch Biochem Biophys 2004, 429:154-163.

59. Re R, Pellegrini N, Proteggente A, Pannala A, Yang M, Rice-Evans C: Antioxidant activity applying an improved ABTS radical cation decolorization assay. Free Radic Biol Med 1999, 26:1231-1237.

doi:10.1186/1477-3155-9-19

Cite this article as: Fang et al: Design and characterization of proteinquercetin bioactive nanoparticles. Journal of Nanobiotechnology 2011 9:19.

\section{Submit your next manuscript to BioMed Central and take full advantage of:}

- Convenient online submission

- Thorough peer review

- No space constraints or color figure charges

- Immediate publication on acceptance

- Inclusion in PubMed, CAS, Scopus and Google Scholar

- Research which is freely available for redistribution

Submit your manuscript at www.biomedcentral.com/submit 